\title{
Effects of Nanosilica on Compressive Strength and Durability Properties of Concrete with Different Water to Binder Ratios
}

\author{
Forood Torabian Isfahani, ${ }^{1}$ Elena Redaelli, ${ }^{1}$ Federica Lollini, ${ }^{1}$ \\ Weiwen Li, ${ }^{2}$ and Luca Bertolini ${ }^{1}$ \\ ${ }^{1}$ Department of Chemistry, Materials and Chemical Engineering “G. Natta”, Politecnico di Milano, Via Mancinelli 7, \\ 20131 Milan, Italy \\ ${ }^{2}$ College of Civil Engineering, Shenzhen University, Nanshan, Shenzhen 518060, China
}

Correspondence should be addressed to Forood Torabian Isfahani; forood.torabian@polimi.it

Received 31 January 2016; Accepted 1 March 2016

Academic Editor: Ying Li

Copyright (c) 2016 Forood Torabian Isfahani et al. This is an open access article distributed under the Creative Commons Attribution License, which permits unrestricted use, distribution, and reproduction in any medium, provided the original work is properly cited.

The effects of the addition of different nanosilica dosages $(0.5 \%, 1 \%$, and $1.5 \%$ with respect to cement) on compressive strength and durability properties of concrete with water/binder ratios $0.65,0.55$, and 0.5 were investigated. Water sorptivity, apparent chloride diffusion coefficient, electrical resistivity, and carbonation coefficient of concrete were measured. The results showed that compressive strength significantly improved in case of water/binder $=0.65$, while for water/binder $=0.5$ no change was found. Increasing nanosilica content, the water sorptivity decreased only for water/binder $=0.55$. The addition of $0.5 \%$ nanosilica decreased the apparent chloride diffusion coefficient for water/binder $=0.65$ and 0.55 ; however, higher nanosilica dosages did not decrease it with respect to reference value. The resistivity was elevated by $0.5 \%$ nanosilica for all water/binder ratios and by $1.5 \%$ nanosilica only for water/binder $=0.5$. The carbonation coefficient was not notably affected by increasing nanosilica dosages and even adverse effect was observed for water/binder $=0.65$. Further information of microstructure was also provided through characterization techniques such as X-ray diffraction, thermal gravimetric analysis, mercury intrusion porosimetry, and scanning electron microscopy. The effectiveness of a certain nanosilica dosage addition into lower strength mixes was more noticeable, while, for the higher strength mix, the effectiveness was less.

\section{Introduction}

In recent years, modification of cement composites by nanoparticles has attracted intense attention among researchers. Concrete, as the most popular cement composite in practical applications, was also subjected to modification by replacing a portion of binder with various nanoparticles such as $\mathrm{TiO}_{2}$ [1], $\mathrm{Fe}_{2} \mathrm{O}_{3}$ [2], $\mathrm{Al}_{2} \mathrm{O}_{3}$ [3], and $\mathrm{SiO}_{2}$. Among those, nanosilica (NS) incorporation into concrete was of interest for many researchers not only because of the similarity of its chemical composition to constituents of C-S-H, but also because of the capability of NS to potentially improve cement composites properties through different mechanisms. NS, as well as silica fume [4], is a highly reactive pozzolan and could consume calcium hydroxide $(\mathrm{CH})$ to form secondary C-S-H $[5,6]$. However, some researchers [7] believe that the addition of NS mostly affects initial silicate polymerization rather than ultimate amount of C-S-H formed. Another mechanism, by which NS can influence cement composite properties, is seeding effect. NS could provide extra sites for the precipitation of hydration products, leading to the acceleration of early stage hydration [5].

The modification of macroscopic properties of concrete by NS addition has been subjected to intensive study. As far as compressive strength is concerned, controversial results were obtained sorting enhancements from notable $[8,9]$ to moderate [10-14], even though no gains were reported $[15,16]$. A certain NS content produced different effects on the strength when NS was incorporated into concrete with different water/cement (w/c) ratios. For instance, employing a content of NS around $1 \%$ NS into concrete with w/c ratio of 0.4 [3] and $0.48[12]$ resulted in quite different gains in 
compressive strength of about $20 \%$ and $12 \%$, respectively. Similarly, utilization of $2 \%$ NS in high volume binary blended concrete with water to binder (w/b) ratio of 0.4 [17] and 0.45 [14] produced null and $16 \%$ strength gain, respectively. Moreover, when such a small content (i.e., 1-2\%) of NS was added, no analogous trend in strength improvement was seen by increasing w/c ratio of concrete of former case from 0.4 to 0.48 (descending trend) and those of latter case from 0.4 to 0.45 (ascending trend). It should be underlined that this discrepancy may have arisen due to the essence of utilized NS in each study such as production method, particle size, agglomeration state (specific surface area), and above all agglomeration state after coming into contact with cement in aqueous media. Even subsequent timing of superplasticizer addition to the mixture plays a role in the effectiveness of NS incorporation on properties of concrete [18].

Concrete is normally reinforced by steel rebars. Besides compressive strength, durability properties are also of high importance, when dealing with reinforced concrete. While strength of concrete containing NS has received particular attention in the last decade, less consideration has been paid to its durability properties. So, recently, there are increasing number of studies in which several durability related properties of cement composites were investigated such as water sorptivity [9, 12, 19-22], resistance to chloride penetration $[12,13,21-24]$, electrical resistivity [22-25], and carbonation resistance $[26,27]$.

Jalal et al. [9] found that the water absorption of concrete decreases with the addition of NS. Similar findings were, also, reported by Supit and Shaikh [19] for water sorptivity of concrete. In another study, Du et al. [12] reported that water absorption and water sorptivity of concrete were not influenced by NS. Quercia et al. [13] obtained that NS addition slightly increased the air content of fresh state concrete. The water absorption of mortar with $\mathrm{w} / \mathrm{c}=0.485$ was reduced by the addition of $2.5 \%$ NS [21], while a little higher content of NS (around 3\%) increased the water absorption of mortar with $\mathrm{w} / \mathrm{c}=0.43$ [26]. As for compressive strength, the same NS addition into mortars with different w/c ratios did not produce corresponding effects. Du et al. [12] and Quercia et al. [13] reported that chloride diffusion coefficient of concrete was reduced by NS addition. According to Madani et al. [24] and Belkowitz et al. [25], the bulk electrical resistivity of concrete samples was increased after the addition of NS.

As far as carbonation resistance is concerned, Rao et al. [26] reported no change in carbonation resistance of mortar containing NS, while Lim and Mondal [27] found that $5 \%$ NS addition to cement paste led to reduction in the degree of carbonation. Although there are some works considering carbonation resistance of cementitious materials, detailed quantitative data on NS impact on the advancement of carbonation in time, especially in concrete, are lacking in the literature.

The impact of NS on the durability properties of concrete, particularly when considering various w/c ratios, is not fully understood. The main goal of this study is to investigate NS effects on the durability properties of concrete such as water sorptivity, resistance to chloride penetration, electrical resistivity, and carbonation resistance. Microstructure
TABLE 1: SSD density, fraction of combination, and absorption of five classes of aggregates.

\begin{tabular}{lccc}
\hline & $\begin{array}{c}\text { SSD density } \\
\left(\mathrm{kg} / \mathrm{m}^{3}\right)\end{array}$ & $\begin{array}{c}\text { Aggregates } \\
\text { combination } \\
(\%)\end{array}$ & $\begin{array}{c}\text { Absorption } \\
(\%)\end{array}$ \\
\hline Sand & 2750 & 35 & 0.2 \\
calc1 & 2750 & 15 & 0.9 \\
calc2 & 2750 & 15 & 0.9 \\
calc3 & 2750 & 15 & 0.9 \\
calc4 & 2750 & 20 & 0.9 \\
\hline
\end{tabular}

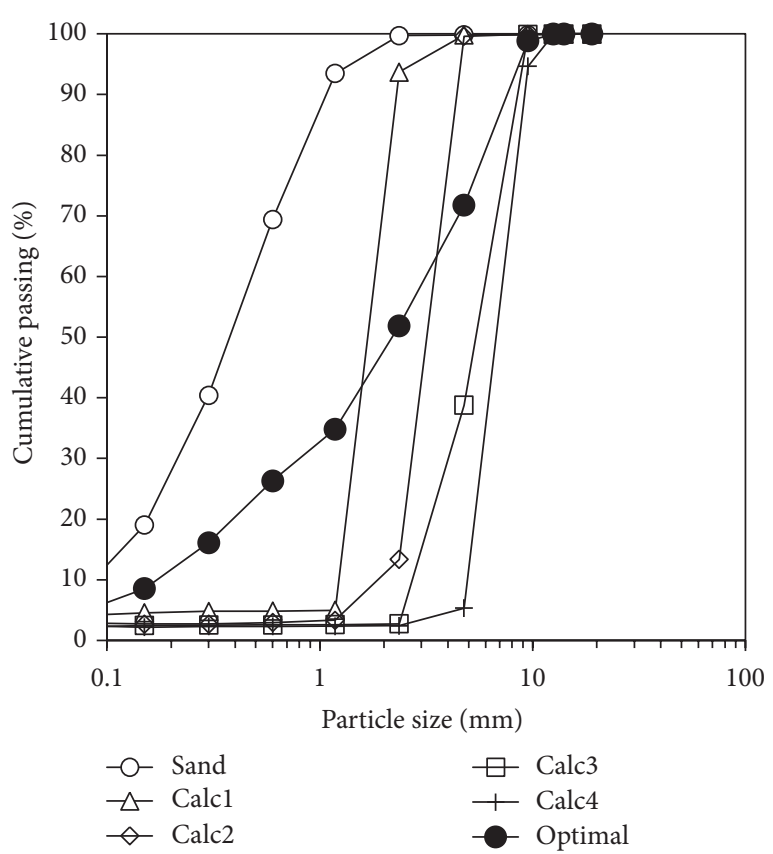

Figure 1: Aggregate size distribution of five different classes: sand, calcl-calc4, and optimal (Fuller's) distribution.

characterization techniques such as X-ray diffraction, thermal analysis, mercury intrusion porosimetry, and environmental scanning electron microscopy were employed to achieve better understanding of how NS influences the factors by which those durability properties are controlled such as $\mathrm{CH}$ content and porosity distribution.

\section{Materials and Experimental Methodology}

2.1. Materials. Concrete was cast with CEM I 42.5R; crushed limestone aggregates, divided in five different classes (sand and calcl-calc4), with maximum size of $12.5 \mathrm{~mm}$ were used; the combination was chosen in order to fit Fuller's grading curve (Figure 1). Saturated surface dried (SSD) density, absorption (\%) and fraction combination of five classes of aggregates are summarized in Table 1. Commercial NS suspension with the concentration of $10 \%$ by weight of water with nominal mean particle size of $20 \mathrm{~nm}$ was used. SEM image of dried NS (Figure 2) shows particle size lower than $100 \mathrm{~nm}$, which could be the agglomeration of 3-4 nanoparticles and it 
TABLE 2: Composition of concrete mixtures and slump values.

\begin{tabular}{|c|c|c|c|c|c|c|c|c|}
\hline \multirow{2}{*}{$\mathrm{w} / \mathrm{b}$} & \multirow{2}{*}{ NS (\%) } & \multicolumn{6}{|c|}{ Composition $\left(\mathrm{kg} / \mathrm{m}^{3}\right)$} & \multirow{2}{*}{ Slump $(\mathrm{mm})$} \\
\hline & & Cement & NS & Water & Sand (SSD) & Coarse aggregate (SSD) & $\mathrm{SP}^{*}$ & \\
\hline \multirow{4}{*}{0.65} & 0 & 308 & - & \multirow{4}{*}{200} & \multirow{4}{*}{924} & \multirow{4}{*}{924} & 1.5 & 175 \\
\hline & 0.5 & 306.5 & 1.5 & & & & 1.5 & 120 \\
\hline & 1 & 304.9 & 3.1 & & & & 1.5 & 75 \\
\hline & 1.5 & 303.4 & 4.6 & & & & 1.5 & 30 \\
\hline \multirow{4}{*}{0.55} & 0 & 344 & - & \multirow{4}{*}{189} & \multirow{4}{*}{924} & \multirow{4}{*}{924} & 2.4 & 240 \\
\hline & 0.5 & 342.3 & 1.7 & & & & 2.4 & 105 \\
\hline & 1 & 340.6 & 3.4 & & & & 2.4 & 40 \\
\hline & 1.5 & 338.8 & 5.2 & & & & 2.4 & 40 \\
\hline \multirow{4}{*}{0.5} & 0 & 366 & - & \multirow{4}{*}{183} & \multirow{4}{*}{922} & \multirow{4}{*}{922} & 1.8 & 50 \\
\hline & 0.5 & 364.2 & 1.8 & & & & 2.6 & 80 \\
\hline & 1 & 362.3 & 3.7 & & & & 3.1 & 150 \\
\hline & 1.5 & 360.5 & 5.5 & & & & 5.5 & 60 \\
\hline
\end{tabular}

${ }^{*}$ Superplasticizer.

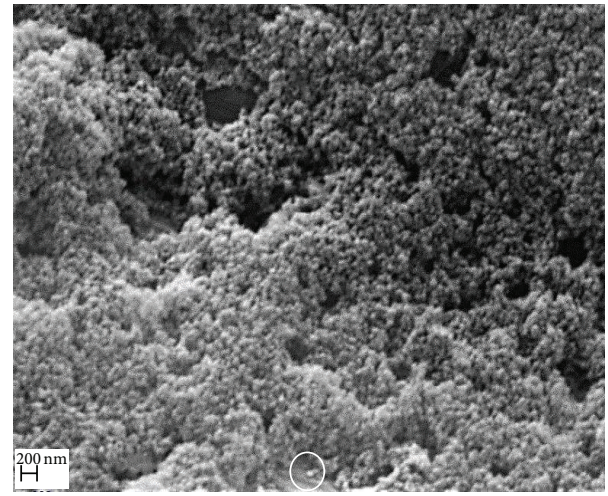

FIGURE 2: SEM micrograph of nanosilica suspension after drying. The white circle shows typical agglomerates of NS with size smaller than $100 \mathrm{~nm}$.

probably was caused by drying process for SEM observation. Particles size distribution and cumulative distribution, conducted by measurement technique of dynamic light scattering (DLS), showed that $51 \%$ of the volume of suspension had particle size finer than $21 \mathrm{~nm}$ and the most probable particle size belongs to $18 \mathrm{~nm}$, that is, $25 \%$ of the suspension volume (Figure 3). Furthermore, only 5\% volume fraction of the tested suspension had the size higher than $100 \mathrm{~nm}$. Thus, NS suspension was well dispersed in water with little degree of agglomeration; however, this did not guarantee uniform dispersion of NS after mixing with solids inside concrete.

2.2. Samples Preparation. Concrete samples with $\mathrm{w} / \mathrm{b}$ ratios of $0.65,0.55$, and 0.5 were cast. The composition of each concrete is shown in Table 2. The mix was designed so that all concrete samples had the same volume of cement paste. For each w/b ratio, three NS contents of $0.5,1$, and $1.5 \%$ with respect to cement mass were considered as replacement of cement. NS suspension was added to the mixing water taking into account water content of suspension and it was stirred manually; then superplasticizer (SP) was added to the water

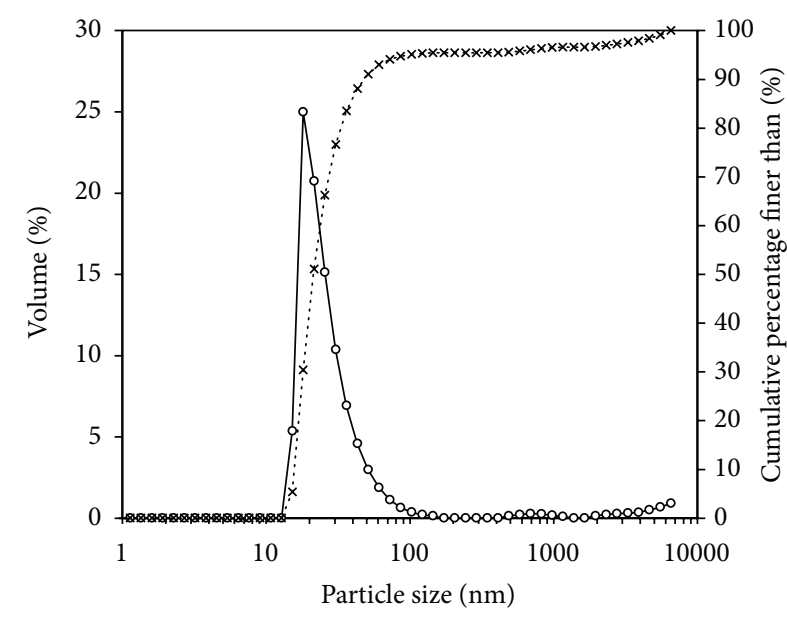

FIGURE 3: Particle size distribution of NS suspension by dynamic light scattering method.

mixture. Cement and aggregates were mixed and then water containing NS and SP was added. For each type of concrete, 4 cubes $100 \times 100 \times 100 \mathrm{~mm}$ were cast for compressive strength; a slab with $500 \times 395 \times 60 \mathrm{~mm}$ dimension was also cast. Cylindrical samples with nominal $100 \mathrm{~mm}$ diameter were cored from the slab at the age of 28 days of curing. The surface in contact with mould (mould surface) was ground, while the casting surface (trowelled surface) remained unchanged. All tests were performed on replicate specimens except chloride diffusion test.

\subsection{Test Methods}

2.3.1. Compressive Strength. The compressive strength test was performed according to EN-12390-3 on cubes moistcured in curing chamber for 7 and 28 days.

2.3.2. Sorptivity and Water Absorption. Capillary water absorption was measured as the mass of liquid absorbed per 
unit surface $\left(i, \mathrm{~kg} / \mathrm{m}^{2}\right)$ of cylindrical specimens in time $t$. The specimens were oven-dried for 1 week at $40^{\circ} \mathrm{C}$ to obtain dry mass and thereafter the mould surface was put in contact with demineralized water. Water sorptivity $\left(S, \mathrm{~kg} / \mathrm{m}^{2} \mathrm{~h}^{0.5}\right)$ was calculated using values at $24 \mathrm{~h}$ according to

$$
i=S \sqrt{t} .
$$

Then, the specimens were immersed in demineralized water until constant mass for calculating total water absorption $W$ (\%) as the difference between saturated mass and dry mass with respect to dry mass.

2.3.3. Chloride Penetration Resistance. Chloride penetration test was carried out according to CEN/TS 12390-11 [28]. The specimens were placed in vacuum container with absolute pressure of $1-5 \mathrm{kPa}$ for $3 \mathrm{~h}$. The container was filled with demineralized water for $1 \mathrm{~h}$ with the pump still running. Soon after, the samples were placed in the lab for $2-4 \mathrm{~h}$ in order for their surface to become dry. All the surfaces but one (mould surface) were covered with epoxy resin and immersed in saturated calcium hydroxide for $18 \mathrm{~h}$ and were finally immersed in sodium chloride solution with concentration of $3 \%$ by mass of solution for 90 days. At the end of the exposure, the specimens were ground to collect powder samples at different depths for acid soluble chloride analysis according to EN 14629 [29]. Chloride content (\%) of each layer was obtained and apparent chloride diffusion coefficient $D_{\text {app }}$ and surface chloride content $C_{S}$ were obtained through the interpolation of the chloride profile according to EN 14629 [29].

2.3.4. Electrical Resistivity. The electrical resistivity test was done by measuring conductance, $G$, across cylindrical specimens. The mould surface of the samples was not ground for this test. The samples were immersed immediately after coring in demineralized water and kept at $20-25^{\circ} \mathrm{C}$ temperature; periodically, for approximately 4 months, the conductance was recorded. The conductance was then converted to electrical resistivity, $\rho$, in $\Omega \mathrm{m}$ using the geometry of the samples:

$$
\rho=\frac{A}{(l G)},
$$

where $A$ and $l$ are surface area and height of the samples.

2.3.5. Carbonation Resistance. Cylindrical specimens were conditioned inside the lab for 14 days with $18-25^{\circ} \mathrm{C}$ temperature and $50-65 \%$ relative humidity and the side surface of the specimens was then covered with epoxy resin. The specimens were placed inside an accelerated carbonation chamber with $4 \% \mathrm{CO}_{2}$ concentration, $55 \pm 5 \%$ relative humidity, and $20^{\circ} \mathrm{C}$ temperature. The depth of carbonation was measured (by $0.5 \mathrm{~mm}$ accuracy) after 45 and 135 days by phenolphthalein indicator. For each surface (trowelled or mould), the reported carbonation depth value was an average of 10 points. The data was interpolated with (3) and carbonation coefficient $K$ $(\mathrm{mm} / \sqrt{ }$ year) was determined (for unidirectional diffusion):

$$
x=K \sqrt{t}
$$

where $x$ is the depth of carbonation in $\mathrm{mm}$ and $t$ is the time in year.

2.3.6. Microstructural Characterization. CH content of concrete samples was estimated by X-ray diffraction (XRD), thermal gravimetric analysis, and differential thermal analysis (TGA/DTA).

Diffracted X-ray patterns were acquired in a range of $2 \theta$ from 15 to 60 degrees with radiation of $\mathrm{Cu}\left(\mathrm{K}_{\alpha}\right)$ tube $(40 \mathrm{kV}$ and $40 \mathrm{~mA}$ ) with $\lambda=1.5418 \AA$, step size of 0.02 degrees, and scan rate of $0.2 \mathrm{deg} / \mathrm{s}$. The Jade software suite version 6 was used to characterize the mineralogical crystalline phases.

TGA/DTA tests were performed using isothermal analyzer on ground fragments of concrete, approximately $100 \mathrm{mg}$. This test was performed under a nitrogen flow of $50 \mathrm{~mL} / \mathrm{min}$. The temperature was programmed rising from ambient temperature of $25^{\circ} \mathrm{C}$ by the rate of $10^{\circ} \mathrm{C} / \mathrm{min}$ up to $900^{\circ} \mathrm{C}$ and temperature was held at $105^{\circ} \mathrm{C}$ for 2 hours to promote evaporation of free water. The amounts of $\mathrm{CH}$ were estimated as

$$
\mathrm{CH}(\%)=\mathrm{WL}_{\mathrm{CH}}(\%) \times \frac{\mathrm{MW}_{\mathrm{CH}}}{\mathrm{MW}_{\mathrm{H}}},
$$

where $\mathrm{CH}$ is the calcium hydroxide weight percentage, $\mathrm{WL}_{\mathrm{CH}}$ corresponds to the percent weight loss associated with $\mathrm{CH}$ decomposition, and $\mathrm{MW}_{\mathrm{CH}}$ and $\mathrm{MW}_{\mathrm{H}}$ are the molecular weight of $\mathrm{CH}(74.01 \mathrm{~g} / \mathrm{mol})$ and water $(18 \mathrm{~g} / \mathrm{mol})$, respectively.

Porosity analysis was conducted by mercury intrusion porosimetry (MIP) and morphology was observed by environmental scanning electron microscopy (ESEM) on concrete fragments collected from broken samples of compressive strength test at 28 days. The samples for MIP, XRD, thermal analysis, and ESEM were selected according to the best performance of compressive strength of concrete incorporating NS compared with the references.

\section{Results}

3.1. Slump and Compressive Strength. The values of slump of fresh concrete are listed in Table 2. Addition of 1.5\% NS significantly decreased the slump from 175 to $240 \mathrm{~mm}$ as reference slumps of concrete with $\mathrm{w} / \mathrm{b}=0.65$ and 0.55 to 30 and $40 \mathrm{~mm}$, respectively. According to Yu et al. [11] this behavior could be explained by the formation of the sort of structure that has high water retention after the addition of NS. Consequently, the amount of lubricating water in the mixture was reduced; thus, viscosity of fresh concrete may increase and slump may decrease. The significant reduction of slump of the concrete incorporating NS could introduce more entrapped air. The slump values for $\mathrm{w} / \mathrm{b}=0.5 \mathrm{did}$ not decrease with respect to reference by increasing NS dosage, since higher amount of SP was used in order to have better workability during casting.

Figure 4 shows compressive strength of concrete after 7 and 28 days of curing as a function of NS content. The 28-days compressive strength of concrete with $\mathrm{w} / \mathrm{b}=$ 0.65 improved considerably by NS addition and showed progressive increase from control value of 33.8 to $47.8 \mathrm{MPa}$ for 

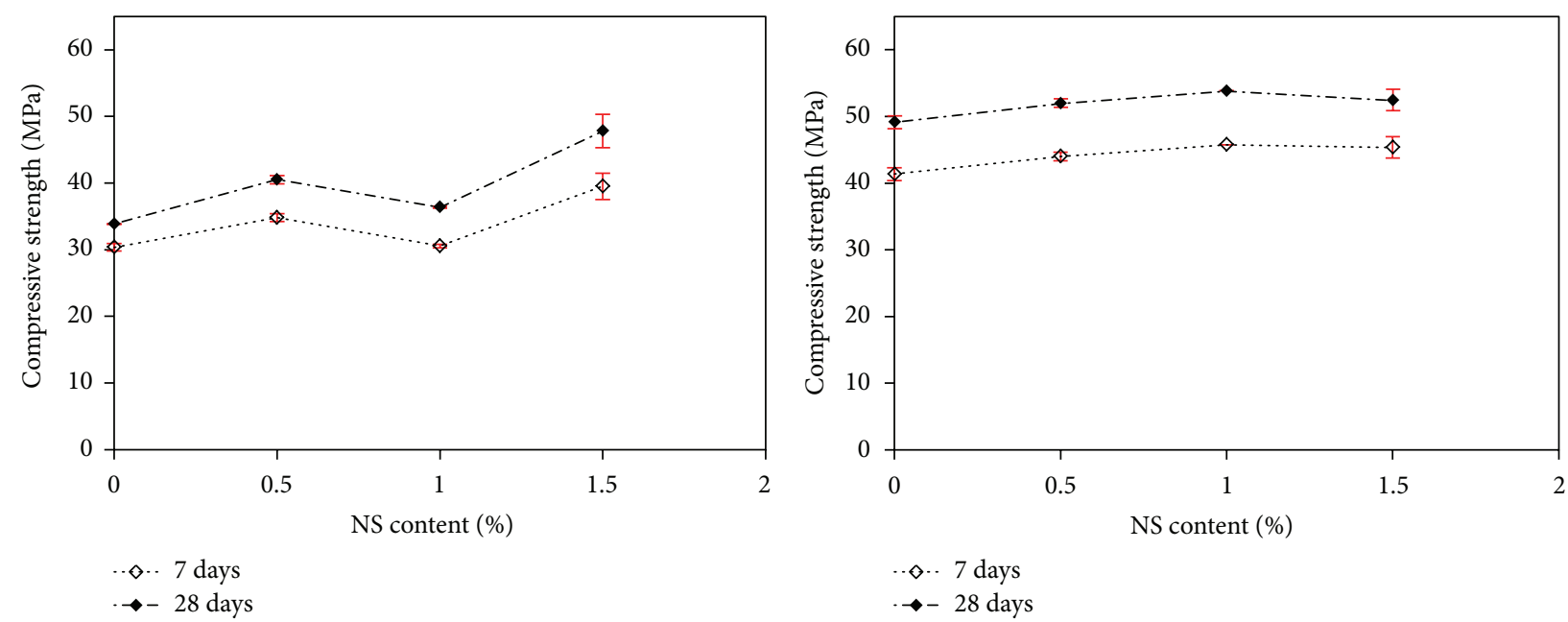

(a)

(b)

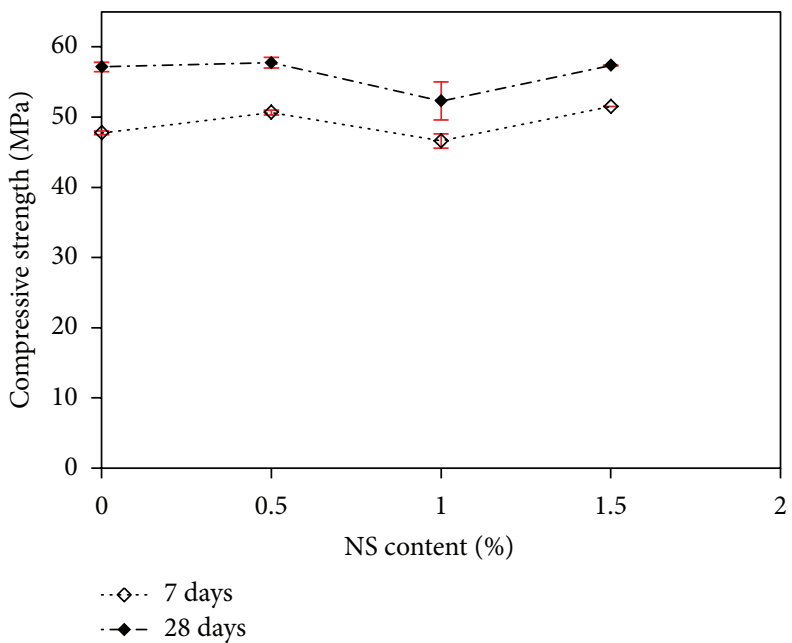

(c)

FIGURE 4: Compressive strength of concrete as a function of NS content (\%) and curing time for w/b ratios: (a) 0.65 , (b) 0.55 , and (c) 0.5 .

$1.5 \%$ NS addition. The compressive strength after 7 days also exhibited progressive improvement from reference value of 30.3 to $39.5 \mathrm{MPa}$ for $1.5 \% \mathrm{NS}$ addition. For $\mathrm{w} / \mathrm{b}=0.55$, the 28 day strength was elevated moderately from control $49.1 \mathrm{MPa}$ to $53.8 \mathrm{MPa}$ with the addition of $1 \% \mathrm{NS}$. The strength at 7 days also showed similar trend as 28 days and increased from 41.3 to $45.7 \mathrm{MPa}$ with $1 \% \mathrm{NS}$. No change was observed in the strength of 28 days of concrete with $\mathrm{w} / \mathrm{b}=0.5$, while 7 -day strength rised from 47.7 to $51.5 \mathrm{MPa}$ with $1.5 \%$ NS.

3.2. Water Sorptivity. Capillary water sorptivity defines the tendency of the concrete to absorb water through capillary suction by which ingress of aggressive substances can occur. As an example, typical curves of water uptake per unit surface, $i$, as a function of square root of time, are shown in Figure 5(a) for reference and $1.5 \%$ NS addition into concrete with $\mathrm{w} / \mathrm{b}=0.65$. The figure shows small variations of $i$ for two replicates for each concrete type. The water uptakes after $24 \mathrm{~h}$ were 1.91 and $2.02 \mathrm{~kg} / \mathrm{m}^{2}$ for control and $1.5 \%$
NS, respectively. From the data of water uptake in time intervals, the average values of water sorptivity coefficient, $S$, $\mathrm{kg} / \mathrm{m}^{2} \mathrm{~h}^{0.5}$ with their variations, were calculated and shown in Figure 5(b) as a function of NS content. For w/b $=0.65$, $0.5 \%$ NS addition slightly decreased the water sorptivity from reference 0.4 to $0.3 \mathrm{~kg} / \mathrm{m}^{2} \mathrm{~h}^{0.5}$ and then the sorptivity reached again around reference value by higher dosages. For $\mathrm{w} / \mathrm{b}=0.55$, it exhibited a clear reduction varying in the range between reference values of 0.34 and $0.2 \mathrm{~kg} / \mathrm{m}^{2} \mathrm{~h}^{0.5}$ by NS incorporation; for $\mathrm{w} / \mathrm{b}=0.5$, it showed slight variation between control values of 0.27 and $0.31 \mathrm{~kg} / \mathrm{m}^{2} \mathrm{~h}^{0.5}$ after NS incorporation.

Figure 5(c) shows the average values of water absorption of concrete as a function of NS content. For $w / b=0.65$, the addition of $0.5 \%$ NS slightly decreased the water absorption from reference value of $3.9 \%$ to $3.6 \%$. For $\mathrm{w} / \mathrm{b}=0.55$, it was clearly reduced from the reference value of $3.8 \%$ to $2.3 \%$ by $1 \% \mathrm{NS}$; for $\mathrm{w} / \mathrm{b}=0.5$, it exhibited a slight variation between values $2.7 \%$ and $3.1 \%$ after NS incorporation. 


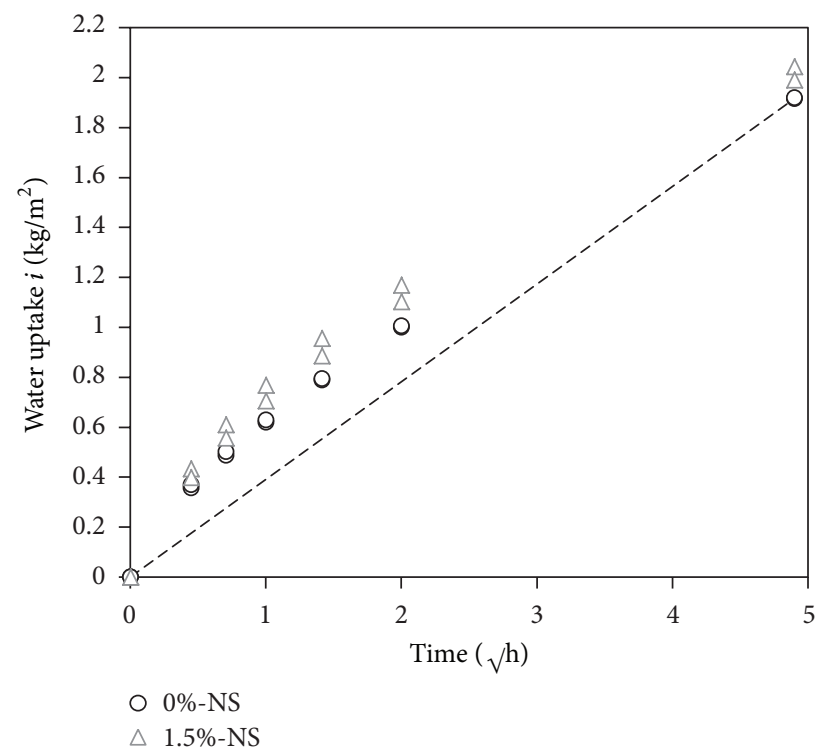

(a)

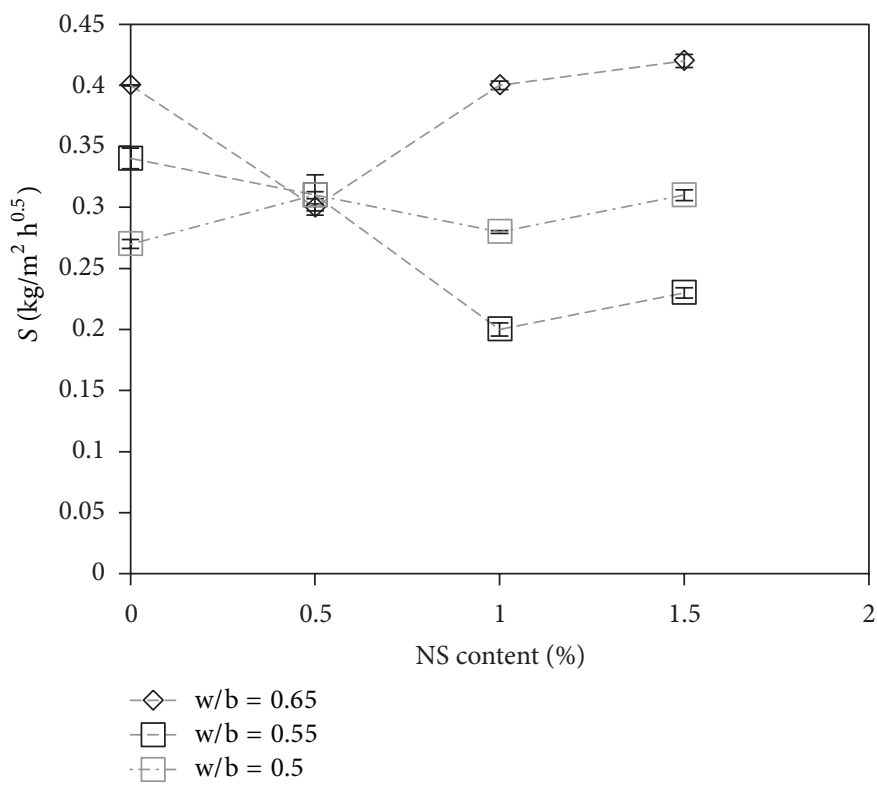

(b)

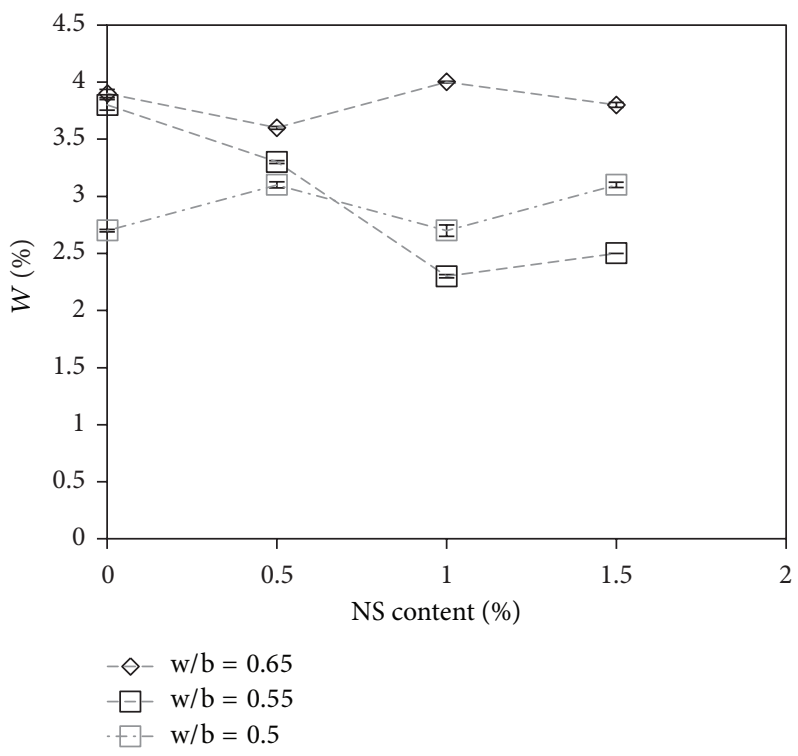

(c)

Figure 5: (a) Example of water uptake as a function of square root of time for w/b $=0.65$. (b) Sorptivity coefficient and (c) water absorption of concrete as a function of NS content.

3.3. Chloride Penetration Resistance. Chloride penetration test was conducted to investigate the resistance of concrete against ingress of chloride ion during a nonstationary diffusion process. As an example, typical chloride content profiles for $\mathrm{w} / \mathrm{b}=0.65$ and $1.5 \%$ NS in comparison with reference are shown in Figure 6(a). From chloride profile interpolation, the apparent chloride diffusion coefficient, $D_{\text {app}}$, and surface chloride content, $C_{S}$, of each concrete were calculated and presented in Figures 6(b) and 6(c), respectively. For $\mathrm{w} / \mathrm{b}=0.65$, the diffusion coefficient slightly decreased from reference value of 19.1 to $15.2 \times 10^{-12} \mathrm{~m}^{2} / \mathrm{s}$ for $0.5 \% \mathrm{NS}$ and unexpectedly increased to $32 \times 10^{-12} \mathrm{~m}^{2} / \mathrm{s}$ for $1 \%$ NS; then it decreased to $18.9 \times 10^{-12} \mathrm{~m}^{2} / \mathrm{s}$ for $1.5 \% \mathrm{NS}$, close to the reference value. For $\mathrm{w} / \mathrm{b}=0.55, D_{\text {app }}$ clearly decreased from control value of 18.1 to $10.4 \times 10^{-12} \mathrm{~m}^{2} / \mathrm{s}$ for $0.5 \% \mathrm{NS}$ and it reached around the reference value with the addition of higher dosages; for $\mathrm{w} / \mathrm{b}=0.5$, initially $D_{\text {app }}$ increased for $1 \%$ NS addition and then it decreased with respect to reference after the addition of $1.5 \%$ NS. The surface chloride content, $C_{S}$, exhibited small variations. For $\mathrm{w} / \mathrm{b}=0.65,0.55$, and 0.5 , the variation range was $0.21-0.26 \%, 0.32-0.35 \%$, and $0.28-$ $0.42 \%$ of mass of concrete, respectively.

3.4. Electrical Resistivity. Electrical resistivity of concrete may be useful for the monitoring and inspection of reinforced concrete structures with regard to reinforcement corrosion 


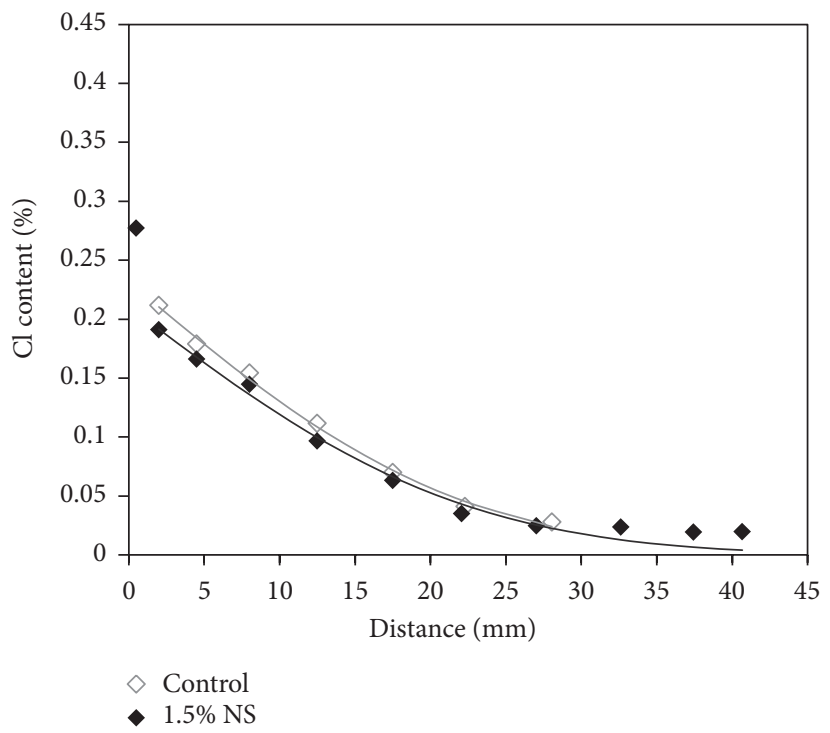

(a)

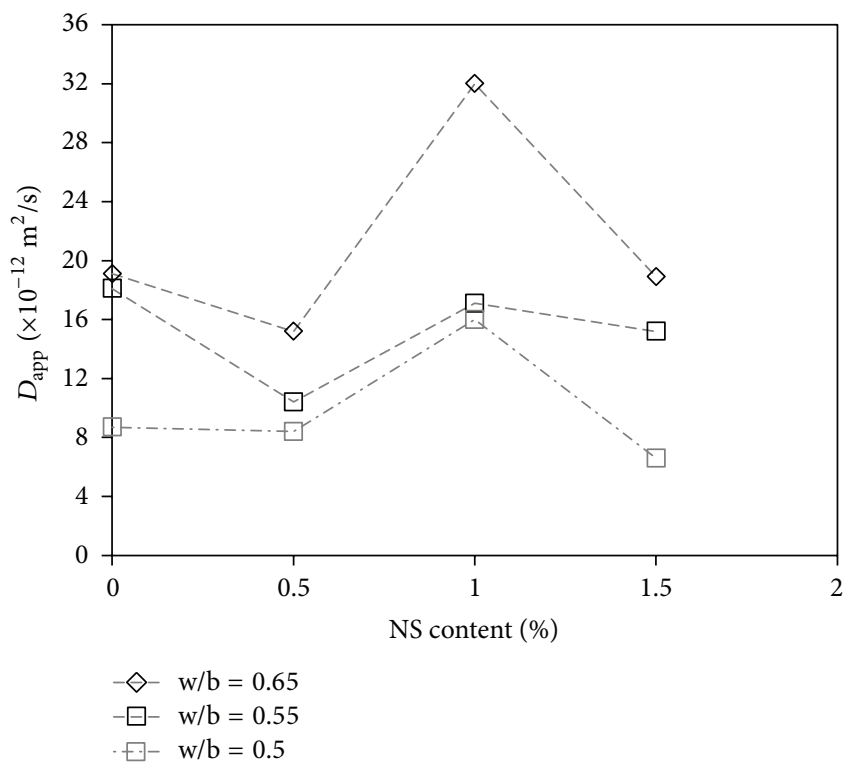

(b)

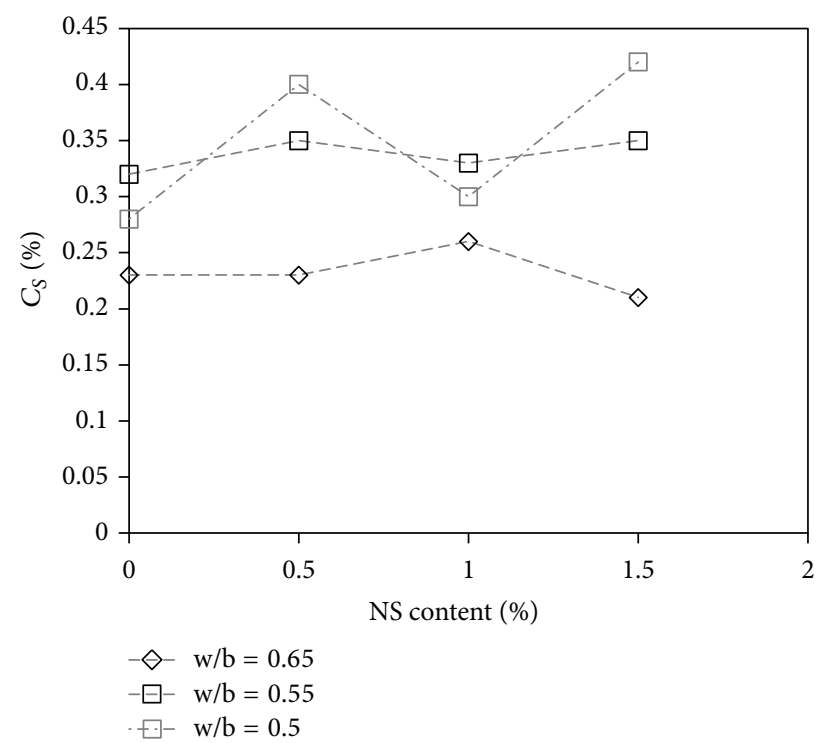

(c)

Figure 6: (a) Example of chloride profile for concrete with w/b $=0.65$ for control and $1.5 \%$ NS addition. (b) Apparent chloride diffusion coefficients and (c) surface chloride content with respect to concrete mass as a function of NS content.

[30] and is a measure of ion permeability of concrete in saturated condition. A denser concrete results in lower permeability and consequently higher electrical resistivity. Immersing concrete samples in water after 28 days of moist curing, hydration of the cement grains continued and porosity and pore connectivity reduced; consequently, the electrical resistivity increased progressively through the time. The electrical resistivity of concrete with $\mathrm{w} / \mathrm{b}=0.65$ for reference and with $1.5 \% \mathrm{NS}$, as an example, as a function of time of immersion for two replicates of each type, is shown in Figure 7(a); zero time is the day of immersion. The average electrical resistivity curves experienced a sudden drop after immersion due to saturation with water and the resistivity after the drop is labeled as $\rho_{i}$. Then, the resistivity increased and the average value after 85 days (labeled as $\rho_{85}$; see Figure $\left.7(\mathrm{a})\right)$ was reported as an indication of the resistivity when hydration degree of cement is close to ultimate. Variations of these two parameters as a function of NS content for all concrete are shown in Figure 7(b). An addition of $0.5 \%$ of NS led $\rho_{i}$ to increase with respect to reference from 53 to $61 \Omega \mathrm{m}$, from 57 to $67 \Omega \mathrm{m}$, and from 69 to $77 \Omega \mathrm{m}$ for concrete with $\mathrm{w} / \mathrm{b}=0.65,0.55$, and 0.5 , respectively; thereafter, by increasing NS dosage, the resistivity of $\mathrm{w} / \mathrm{b}=0.65$ and 0.55 did not considerably change as compared to reference. Comparing the resistivity of concrete with $\mathrm{w} / \mathrm{b}=0.5$ to those of 0.65 and 0.55 , a different behavior was observed. The highest reading of $\rho_{i}$ was $87 \Omega \mathrm{m}$ for $1.5 \% \mathrm{NS}$ with $\mathrm{w} / \mathrm{b}=0.5$. The value of $\rho_{85}$ is an indication 


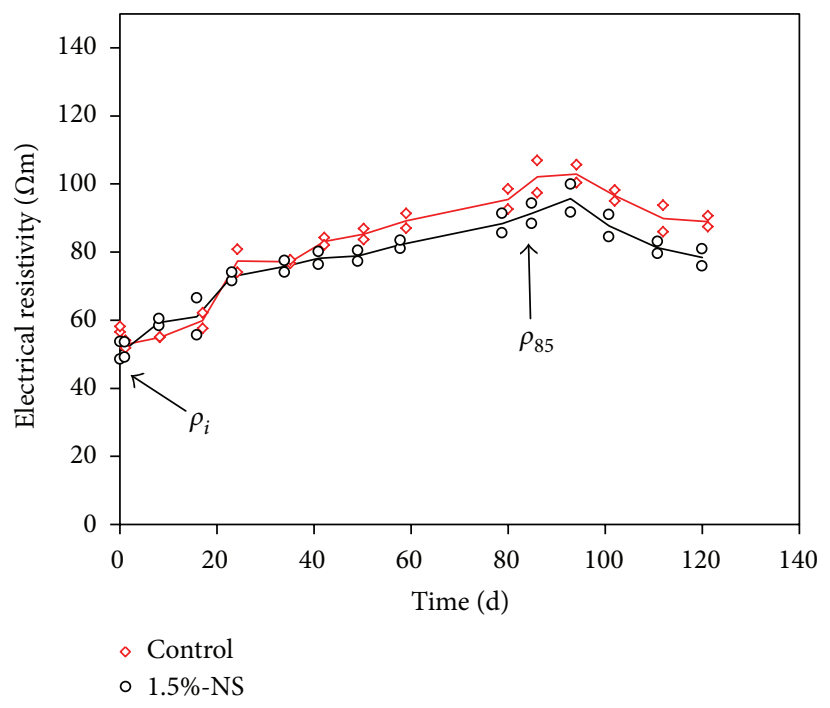

(a)

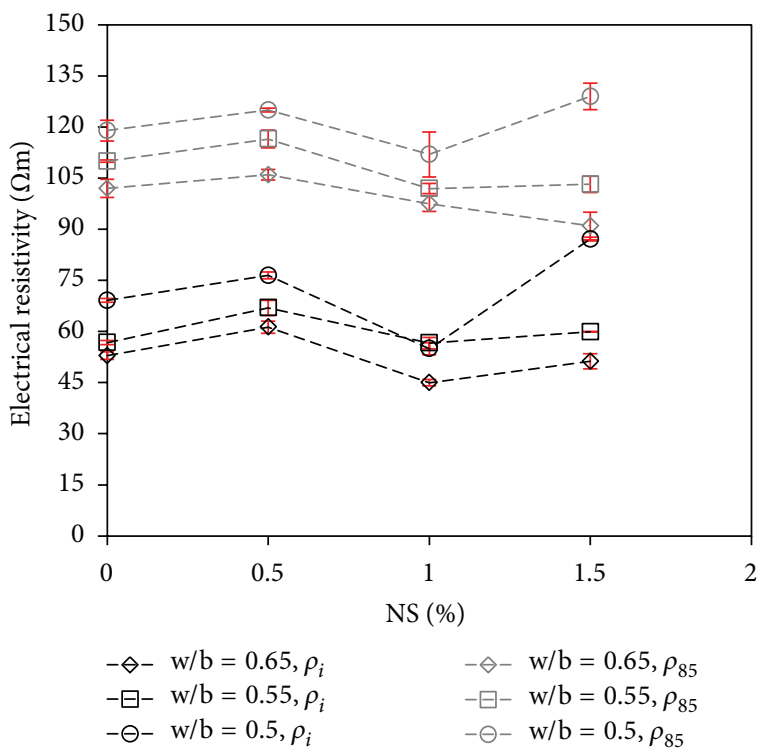

(b)

Figure 7: (a) Electrical resistivity of concrete with $\mathrm{w} / \mathrm{b}=0.65$ immersed in water after curing for 28 days for control and $1.5 \%$ NS addition. The solid lines express average values of the two data points. Initial resistivity, $\rho_{i}$, and resistivity of 85-day immersion, $\rho_{85}$, are also shown and (b) their average values with their variations as a function of NS content.

of permeability of each concrete when hydration degree of cement grains in the concrete is close to ultimate and showed approximately similar trend with that of $\rho_{i}$ by increasing NS content.

3.5. Carbonation Resistance. A typical curve of carbonation depth versus time of exposure is presented in Figure 8(a) for trowelled surface of $\mathrm{w} / \mathrm{b}=0.65$ and $1.5 \% \mathrm{NS}$ in comparison with reference. The carbonation depth increased from $14.1 \mathrm{~mm}$ for reference to $17.5 \mathrm{~mm}$ for $1.5 \% \mathrm{NS}$ after 135 days of exposure. Carbonation coefficient, $K$, is known as a slope of the interpolated line in the figure and is depicted in Figures 8(b) and 8(c) as a function of NS content for trowelled and mould surfaces, respectively. For $\mathrm{w} / \mathrm{b}=0.65$ and trowelled surface, $K$ increased from control of 24 to a maximum of $29.3 \mathrm{~mm} / \sqrt{ }$ year for $1 \% \mathrm{NS}$ addition, while, for $\mathrm{w} / \mathrm{b}=0.55, K$ was reduced from 20.8 to a minimum of $16 \mathrm{~mm} / \sqrt{ }$ year for $1 \%$ NS. For $\mathrm{w} / \mathrm{b}=0.5$, no significant changes for $K$ values were observed. Comparing Figures 8(b) with 8(c), the $K$ values for trowelled surface were slightly higher than those of mould surface, probably because trowelled surface was affected by bleeding. It is known that the carbonation resistance depends on various factors such as $\mathrm{CH}$ content and porosity of concrete. For this sake, $\mathrm{CH}$ contents of each concrete type were evaluated qualitatively by $\mathrm{XRD}$ analysis and more quantitatively by thermal analysis in order to describe the carbonation results.

\subsection{Microstructural Characterization}

3.6.1. X-Ray Diffraction. Figure 9 shows XRD pattern of selected concrete samples represented by intensity counts/s versus diffraction angle $(2 \theta)$. Intense peaks of dolomite $\left(\mathrm{CaMg}\left(\mathrm{CO}_{3}\right)_{2}\right)$ and calcite $\left(\mathrm{CaCO}_{3}\right)$ coming from calcareous
TABLE 3: CH contents by weight for selected concrete samples, calculated from thermal analysis.

\begin{tabular}{lccc}
\hline $\mathrm{w} / \mathrm{b}$ & $\mathrm{NS}(\%)$ & $\mathrm{WL}_{\mathrm{CH}}(\%)$ & $\mathrm{CH}$ content $(\%)$ \\
\hline 0.65 & 0 & 1.21 & 4.98 \\
0.65 & 1.5 & 1.29 & 5.30 \\
0.55 & 0 & 1.01 & 4.15 \\
0.55 & 1 & 0.98 & 4.03 \\
0.5 & 0 & 1.23 & 5.06 \\
0.5 & 1.5 & 0.66 & 2.71 \\
\hline
\end{tabular}

aggregates are visible in the figure. Intensity counts of peaks of $2 \theta=18.1^{\circ}$ are associated with the main peak of $\mathrm{CH}$ crystals. Comparing the intensity of this peak of control with NS containing concrete, it was found that $\mathrm{CH}$ content only decreased in concrete with $\mathrm{w} / \mathrm{b}=0.5$ after NS addition. This result was further investigated with thermal analysis.

3.6.2. Thermal Analysis. Figure 10 shows as an example the TGA/DTA graphs for concrete with $\mathrm{w} / \mathrm{b}=0.65$ and $1.5 \%$ NS in comparison with control. The $\mathrm{CH}$ weight loss (in range of $420-510^{\circ} \mathrm{C}$ ) and dolomite and calcium carbonate weight losses $\left(720-810^{\circ} \mathrm{C}\right.$ and $820-890^{\circ} \mathrm{C}$, resp.) are shown using DTA peaks. The calculated $\mathrm{CH}$ contents using (4) are listed in Table 3 . The $\mathrm{CH}$ content of concrete with $\mathrm{w} / \mathrm{b}=0.5$ sharply decreased from reference value of $5.06 \%$ to $2.71 \%$ by weight. In contrast, $\mathrm{CH}$ content for other concrete types practically exhibited no change by NS incorporation. This outcome is in accordance with the findings of XRD analysis.

3.6.3. Porosity and Pore Size Distribution. Figures 11(a), 11(b), and $11(\mathrm{c})$ report differential pore distribution $(\mathrm{d} V / \mathrm{d} \log D)$, that is, the relationship between pore volume, $V$, and pore 


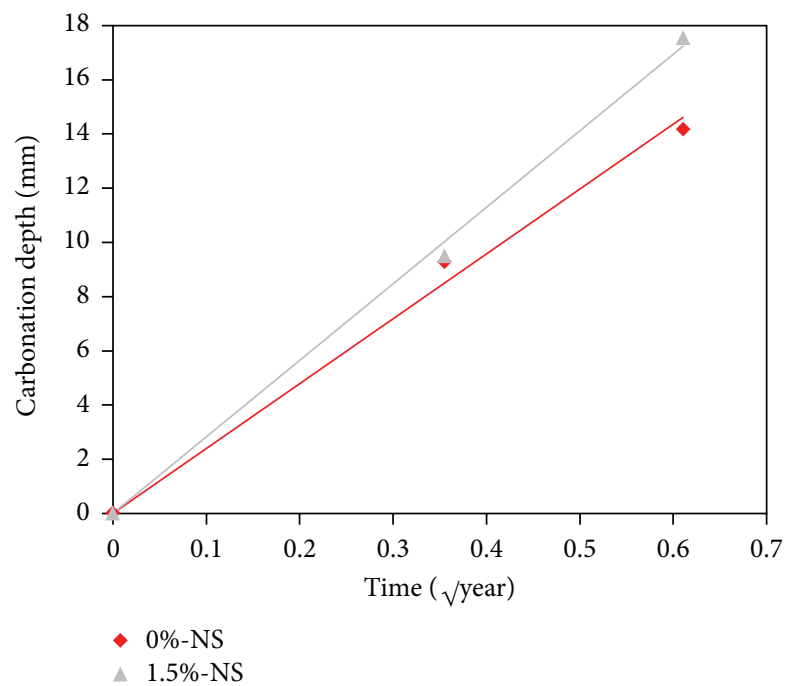

(a)

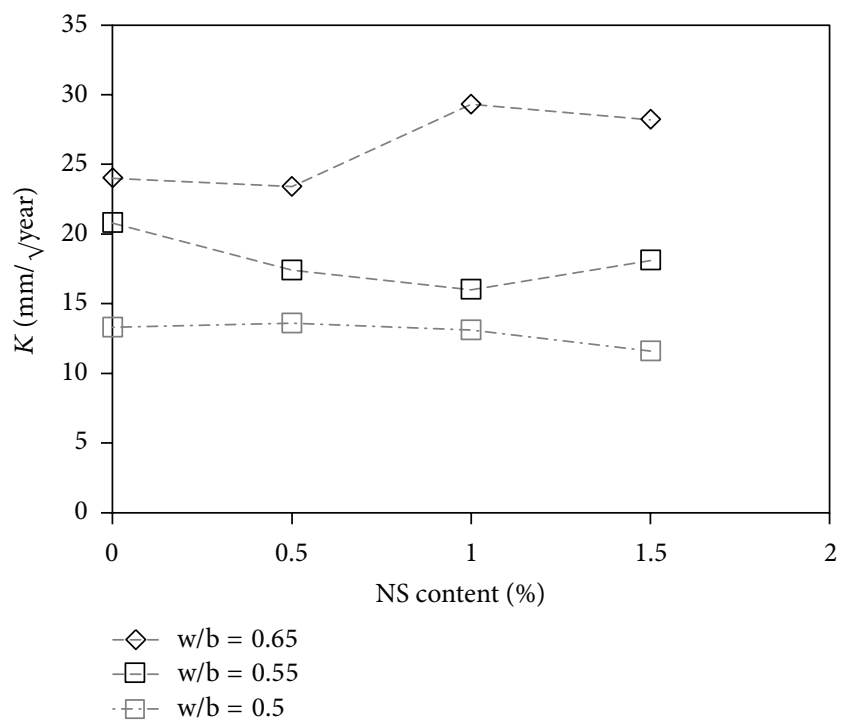

(b)

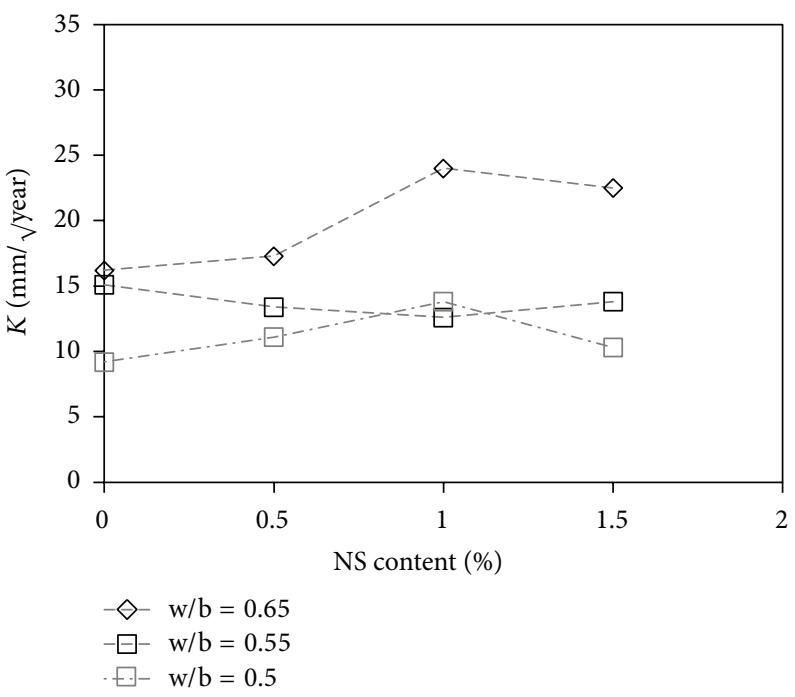

(c)

FIGURE 8: (a) Example of carbonation depth as a function of square root of time of exposure at $4 \% \mathrm{CO}_{2}$ and interpolated lines for trowelled surface of reference and $1.5 \%$ addition into concrete with $\mathrm{w} / \mathrm{b}=0.65$. Carbonation coefficients of (b) trowelled and (c) mould surface of concrete as a function of NS content.

size, $D$, in the range of $6 \mathrm{~nm}$ to few hundreds $\mu \mathrm{m}$ for different specimens. The higher is the value of $\mathrm{d} V / \mathrm{d} \log D$, the higher is the pore volume fraction related to a certain pore size with respect to total porosity volume. Cumulative intrusion volume $(\mathrm{mL} / \mathrm{g})$ is depicted in Figures 11(d), 11(e), and 11(f). Pores in the range $\leq 10 \mathrm{~nm}, 10-50 \mathrm{~nm}$, and $50-10000 \mathrm{~nm}$ are classified according to [31] as gel pores, micropores, and macropores, respectively, and porosity percentage of each category is also shown in Figures 11(d), 11(e), and 11(f). Gel pores do not contribute to strength and permeability, unlike the micro- and macropores that influence strength and durability properties. Total intrusion volume, total porosity (\%), and median pore size (nm) are presented in Table 4 .

Figures 11(a) and 11(d) show that macroporosity for $\mathrm{w} / \mathrm{b}=$ 0.65 and total porosity (Table 4 ) did not change by $1.5 \%$ NS addition with respect to reference; limited refinement was observed in microporosity by NS addition. The gel porosity was elevated considerably by $1.5 \%$ NS addition with respect to reference. This could be an indication of higher C-S$\mathrm{H}$ gel formed when NS was incorporated $[13,14]$. From Figures $11(\mathrm{~b})$ and $11(\mathrm{e})$, for $\mathrm{w} / \mathrm{b}=0.55$, the micro- and macroporosity and the total porosity (Table 4 ) were clearly reduced with respect to control. The gel porosity increased moderately but not as much as that of $w / b=0.65$. Finally, for $\mathrm{w} / \mathrm{b}=0.5$, Figures $11(\mathrm{c})$ and $11(\mathrm{f})$ reveal that microporosity did not change after 1.5\% NS addition, while macroporosity showed slight reduction with respect to control. Table 4 shows that the total porosity moderately decreased with respect to reference and the reduction was smaller than that of $\mathrm{w} / \mathrm{b}=0.55$. The gel porosity was raised by $1.5 \% \mathrm{NS}$ but, 
TABLE 4: Total porosity percentage, median pore diameter and intrusion volume of pores for selected concrete mixes.

\begin{tabular}{lcccc}
\hline $\mathrm{w} / \mathrm{b}$ & NS (\%) & Porosity $(\%)$ & Median pore diameter $(\mathrm{nm})$ & Total intrusion volume $(\mathrm{mL} / \mathrm{g})$ \\
\hline 0.65 & 0 & 16.525 & 115.7 & 0.072 \\
0.65 & 1.5 & 16.679 & 103.2 & 0.074 \\
0.55 & 0 & 15.542 & 119.4 & 0.068 \\
0.55 & 1 & 12.762 & 115.7 & 0.055 \\
0.5 & 0 & 12.162 & 106.2 & 0.052 \\
0.5 & 1.5 & 11.102 & 100.6 & 0.046 \\
\hline
\end{tabular}

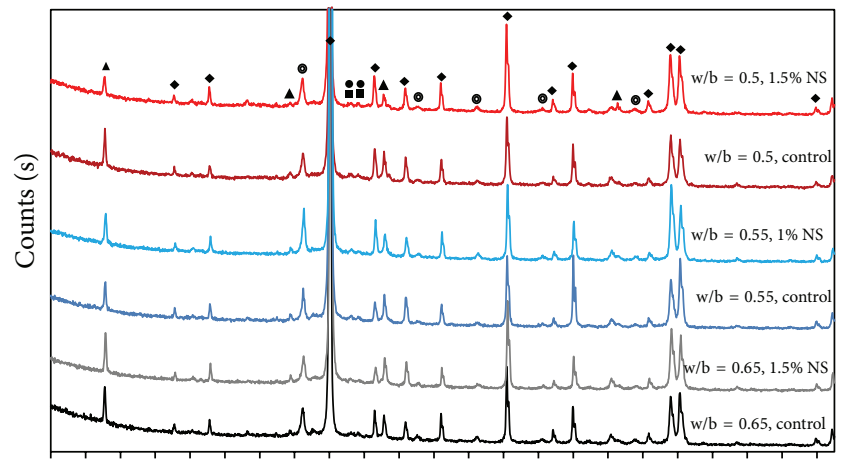

1517192123252729313335373941434547495153555759 $2 \theta\left(^{\circ}\right)$

A Portlandite

- $\beta$-C2S (larnite)

- Calcite

- $\mathrm{C} 3 \mathrm{~S}$

FIGURE 9: XRD pattern for concrete containing NS.

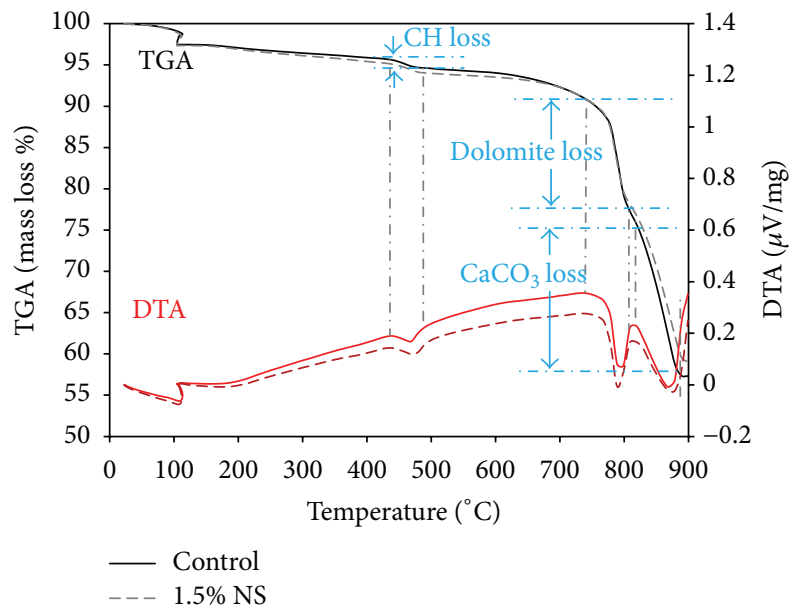

FIGURE 10: TGA/DTA plots of reference and $1.5 \%$ NS addition into concrete with $\mathrm{w} / \mathrm{b}=0.65$ versus temperature range from 25 to $900^{\circ} \mathrm{C}$.

in comparison with the other two w/b ratios, was of minor concern.

3.6.4. Morphology Observation. Micrographs of concrete, as an example, for reference and $1.5 \%$ NS with $\mathrm{w} / \mathrm{b}=0.65$, are depicted in Figure 12. Large plates of $\mathrm{CH}$ and ettringite needles are clearly visible in Figure 12(a) as shown with solid and hollow arrows, respectively. As expected, no sign of partially reacted NS was seen in Figure 12(b) in contrast to [18] who claimed the observation of unreacted NS agglomeration after 28 days of curing. It seems that NS was fully reacted and NS was no longer visible. The morphology of concrete with NS, Figure 12(b), exhibited a rather granular surface compared with plain concrete; this could be due to $\mathrm{C}-\mathrm{S}-\mathrm{H}$ precipitates around NS. Furthermore, the concrete containing NS showed more uniform morphology having less visible macropores with respect to reference, as indicated in the figure by white arrows.

\section{Discussion}

In order to evaluate the effects of partial replacement of cement with NS on macroscopic properties of concrete with various $\mathrm{w} / \mathrm{b}$ ratios, initially the relation between the compressive strength and NS content for a specific w/b ratio is considered. Then, the effect of a certain NS content on compressive strength of concrete fabricated with different $\mathrm{w} / \mathrm{b}$ ratios is explored. Similarly, for durability properties, the role of different NS dosages in a specific w/b ratio is described. Finally, the effect of a certain NS content on the properties of concrete with various $\mathrm{w} / \mathrm{b}$ ratios is investigated.

The results presented in Section 3.1 reflect beneficial effect of NS on 7-day strength of concrete; see Figure 4 . For each w/b ratio, increasing NS content mostly increased the strength of 7 days with respect to reference. This beneficial effect could be attributed to the accelerating effect of NS on early cement hydration. The strength of 28 days exhibited slightly different behavior, increasing NS dosage. It showed generally ascending trend as a function of NS content for $\mathrm{w} / \mathrm{b}=0.65$; it increased with a gentle slope and reached a maximum after $1 \%$ NS addition for $w / b=0.55$. For $w / b=0.5$, Figure $4(\mathrm{c})$ shows that the strength did not vary with increasing NS dosage.

For investigating the effect of a certain NS dosage on compressive strength of concrete with various $\mathrm{w} / \mathrm{b}$ ratios, the strength of 7 and 28 days of concrete is depicted as a function of w/b ratio in Figure 13. For each NS dosage, the experimental data are fitted through an exponential relationship according to Abram's law [32]. Each line is illustrative of a certain NS dosage and represents a specific exponential relationship between the strength and $\mathrm{w} / \mathrm{b}$ ratio. According to Figure 13(a), for 7-day strength, the fitted lines have converging tendency towards reference (black line) by reducing $\mathrm{w} / \mathrm{b}$ ratio. Decreasing $\mathrm{w} / \mathrm{b}$ ratio, distance between each line and reference line decreased; thus, the strength 


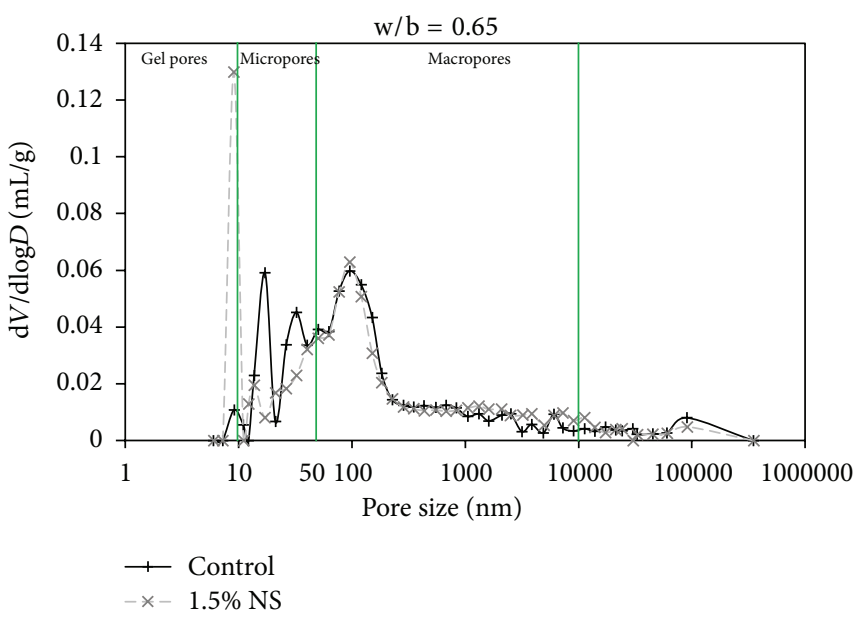

(a)

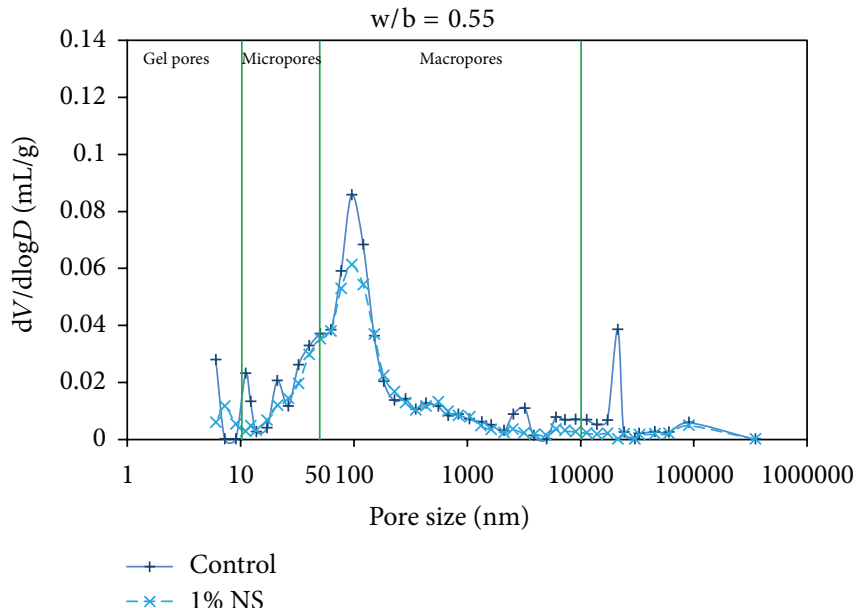

(b)

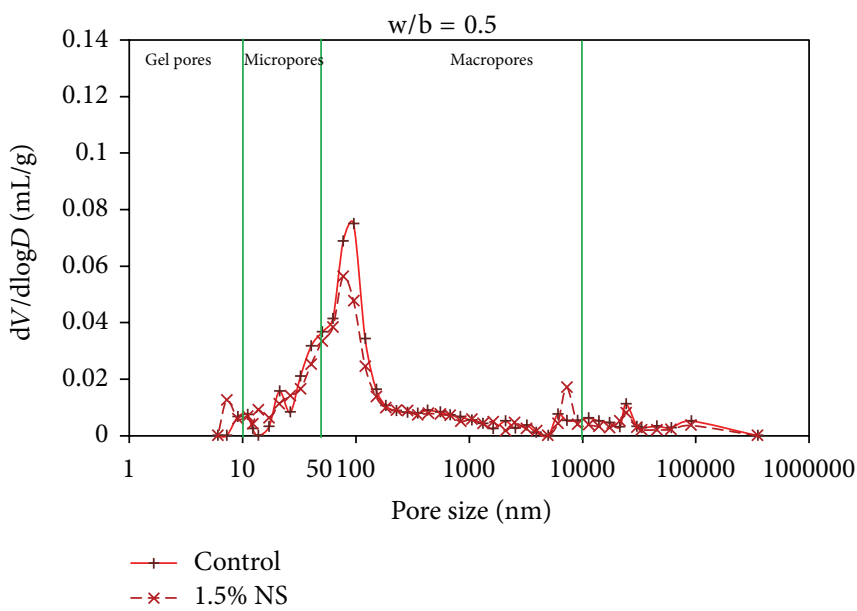

(c)

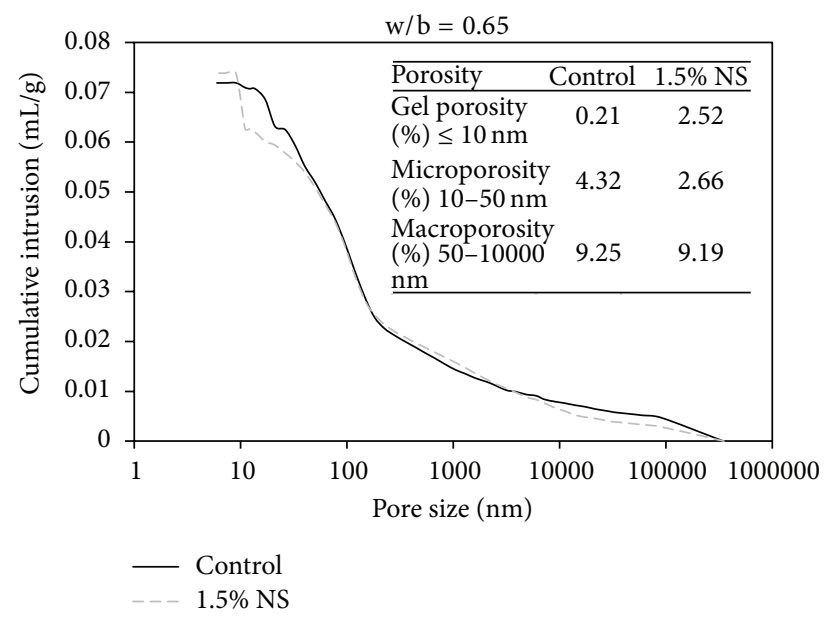

(d)

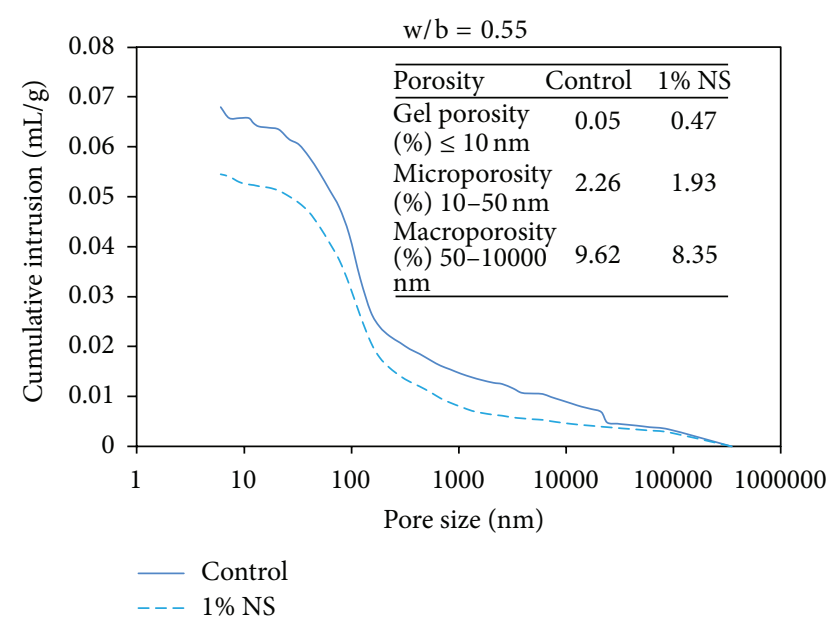

(e)

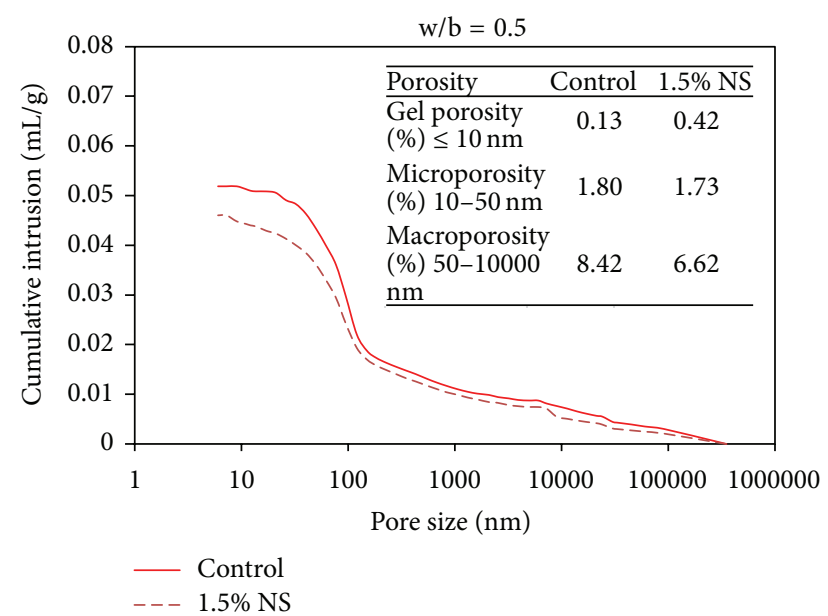

(f)

Figure 11: Pore size distribution and cumulative intrusion volume of selected specimens of concrete.

enhancement decreased as well. Accordingly, for $\mathrm{w} / \mathrm{b}=0.65$, the strength enhancement was larger than that of $\mathrm{w} / \mathrm{b}=$ 0.55 and 0.5 . For 28-day strength in Figure 13(b), converging the tendency of the lines is even more pronounced than 7-day strength when w/b decreases. Considerable enhancement relative to reference was detected for $w / b=0.65$. For $\mathrm{w} / \mathrm{b}=0.55$, the enhancement was smaller than $\mathrm{w} / \mathrm{b}=0.65$. Finally, for $\mathrm{w} / \mathrm{b}=0.5$, no enhancement was found after 


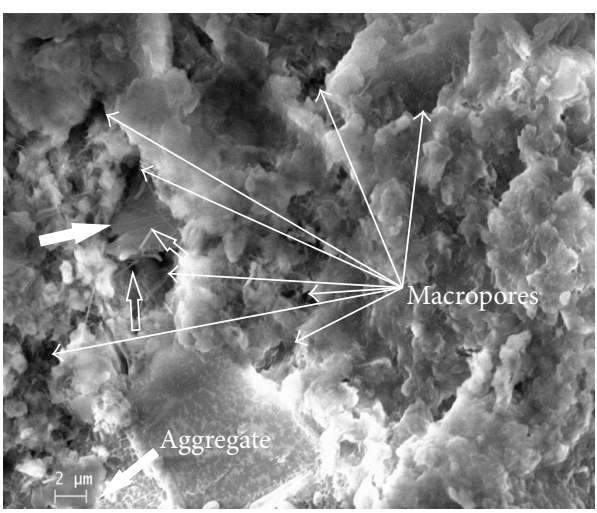

(a)

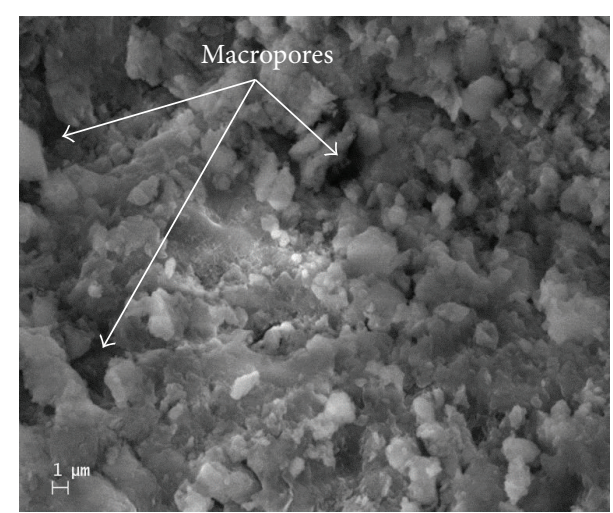

(b)

FIGURE 12: ESEM images of concrete with $\mathrm{w} / \mathrm{b}=0.65$ : (a) control and (b) with $1.5 \%$ NS addition. CH plates (solid arrows) and ettringite needles (hollow arrows) are also visible in (a).

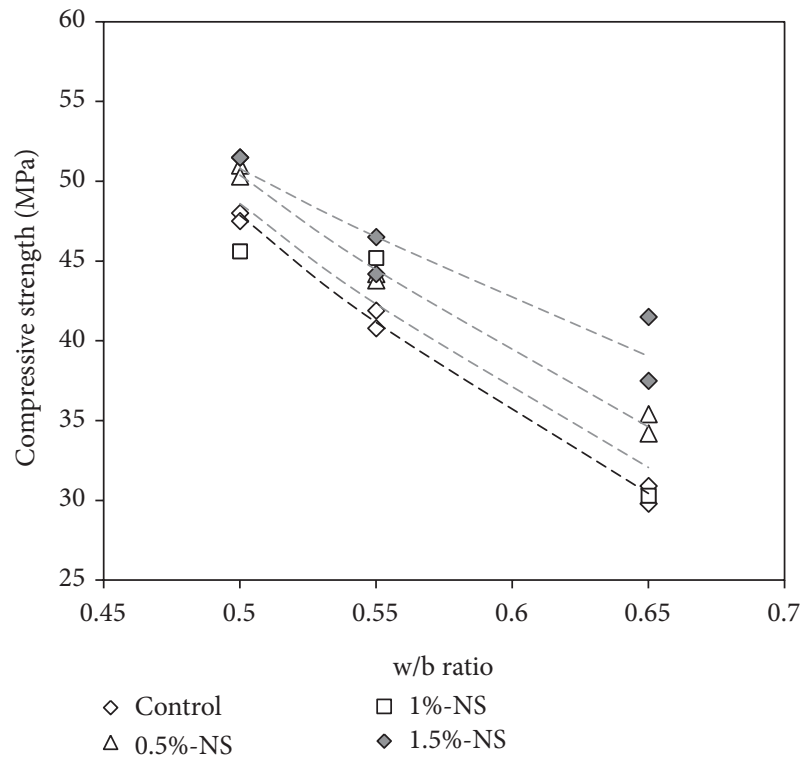

(a)

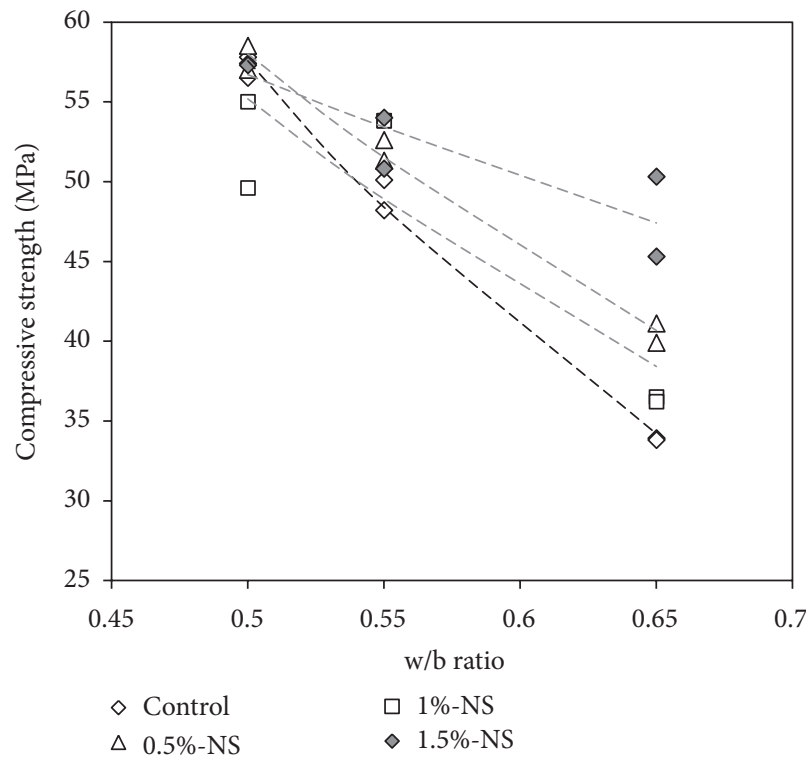

(b)

FIGURE 13: Compressive strength of concrete as a function of w/b ratio: (a) 7 days and (b) 28 days of curing. Dashed lines represent interpolated values according to Abram's law. The black line represents reference concrete.

the addition of NS and the lines approximately approached the reference line. The effect of a certain NS dosage was more pronounced at the lower strength mixes (higher w/b ratio). For the higher strength $\operatorname{mix}$ (lower $\mathrm{w} / \mathrm{b}$ ratio), the effect was less. The reason probably relates to the reduction of distance between cement grains, when w/b ratio is reduced. Decreasing the distance, packing, and accelerating effects of NS may differ.

Among 28-day strength enhancements obtained above for concrete containing NS, remarkable enhancement of $41 \%$ with respect to reference was obtained for $\mathrm{w} / \mathrm{b}=0.65$ and $1.5 \%$ NS addition. This enhancement could be related to higher amount of C-S-H formed as a consequence of NS addition, as indicated by the porosity analysis (Figure 11(d)). In addition, NS led to more uniform morphology than reference concrete as evidenced by ESEM micrographs.
The notable improvement in the strength could be an intriguing outcome for sustainable concrete technology, even though such a high w/b ratio is not commonly employed in practical applications. The 28-day strength was elevated to $47.8 \mathrm{MPa}$, which is close to that of reference concrete with $\mathrm{w} / \mathrm{b}=0.55$ (i.e., $49.2 \mathrm{MPa}$ ). This means that the same strength can be obtained by increasing $\mathrm{w} / \mathrm{b}$ ratio from 0.55 to 0.65 and by the addition of NS $\left(4.6 \mathrm{~kg} / \mathrm{m}^{3}\right.$; see Table 2$)$, reducing cement content of $36 \mathrm{~kg} / \mathrm{m}^{3}$.

The results presented in Section 3.2 reveal that no clear effect of NS incorporation into concrete on water sorptivity for $\mathrm{w} / \mathrm{b}=0.65$ and 0.5 was detected. In contrast, for $\mathrm{w} / \mathrm{b}=0.55$, by increasing NS dosage, the sorptivity clearly decreased to a minimum after $1 \%$ NS. For resistance to chloride penetration, no comprehensible trend as a function of NS dosage was observed for concrete with various w/b 

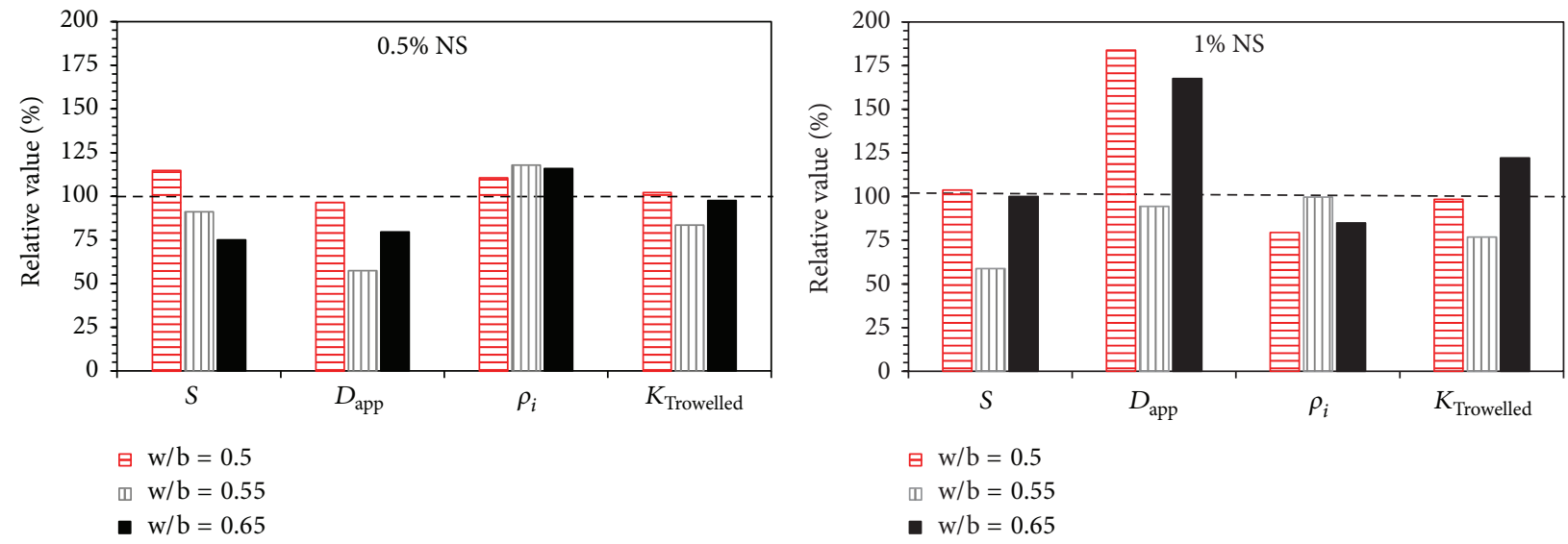

(a)

(b)

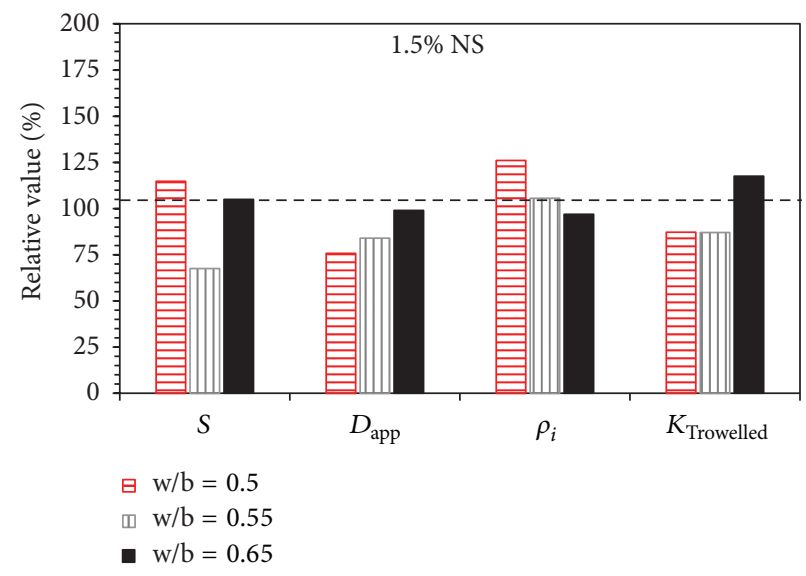

(c)

FIGURE 14: Effect of NS addition on concrete with different w/b; expressed as relative value of each parameter with respect to reference: (a) $0.5 \%$ NS addition, (b) $1 \%$ NS addition, and (c) $1.5 \%$ NS addition.

ratios. For electrical resistivity, a similar trend as a function of NS dosage was detected for $\mathrm{w} / \mathrm{b}=0.65$ and 0.55 . A comparative increase was observed when $0.5 \%$ NS was added; thereafter, with the increasing NS content, the resistivity decreased. Trend of variation of carbonation coefficient with the increase of NS content for $\mathrm{w} / \mathrm{b}=0.65,0.55$, and 0.5 was ascendant, descendent, and horizontal, respectively.

In order to investigate the relationship between $\mathrm{w} / \mathrm{b}$ ratio and the effectiveness of a certain NS dosage on durability properties, measured parameters such as sorptivity $(S)$, chloride diffusion $\left(D_{\text {app }}\right)$, electrical resistivity $\left(\rho_{i}\right)$, and carbonation coefficient of trowelled surface $\left(K_{\text {trowelled }}\right)$ of concrete with different $\mathrm{w} / \mathrm{b}$ ratios but containing a certain NS dosage are compared. Relative values (\%) of a generic parameter for concrete with $\mathrm{w} / \mathrm{b}=0.65,0.55$, and 0.5 are shown in Figures 14(a), 14(b), and 14(c) for 0.5\%, 1\%, and $1.5 \%$ of NS, respectively. For a generic property, the relative value is defined as the ratio between the generic parameter for samples containing NS and that of the corresponding control with similar $\mathrm{w} / \mathrm{b}$ ratio and curing time, multiplied by 100 . A value above $100 \%$ shows an increase in the considered property, whilst a value below $100 \%$ shows a decrease.
As far as sorptivity of concrete is concerned, a certain NS addition into concrete with different $w / b$ ratios did not produce clear effect. Comparing Figures 14(a) with 14(b) and 14 (c), an addition of $0.5 \%$ NS into concrete with $\mathrm{w} / \mathrm{b}=0.65$ and 0.55 led to slight decrease in water sorptivity with respect to reference and for $\mathrm{w} / \mathrm{b}=0.5$ led to slight increase; however, this tendency was not maintained when higher dosages were incorporated. An addition of $1 \%$ and $1.5 \%$ NS led to no appreciable change in the sorptivity of $\mathrm{w} / \mathrm{b}=0.65$ and 0.5 with respect to reference; on the contrary, the same contents of NS led to a reduction in the sorptivity of concrete with $\mathrm{w} / \mathrm{b}=0.55$.

As far as chloride penetration resistance is concerned, a certain NS dosage showed different effects on the chloride diffusion coefficient of concrete with different $w / b$ ratios. Comparing Figures 14(a) with 14(c), 0.5\% NS seems to be effective to promote concrete resistance to chloride penetration for $\mathrm{w} / \mathrm{b}=0.65$ and $0.55 ; 1.5 \%$ NS reduced the chloride diffusion coefficient of $\mathrm{w} / \mathrm{b}=0.5$ and 0.55 . Thus, the tendency of reduction as a function of w/b ratio in Figure 14(a) was not maintained in Figure 14(c). Different factors are mentioned in the literature as an explanation for reducing chloride diffusivity by NS. For instance, for $\mathrm{w} / \mathrm{b}=0.5$ and $1.5 \%$ 


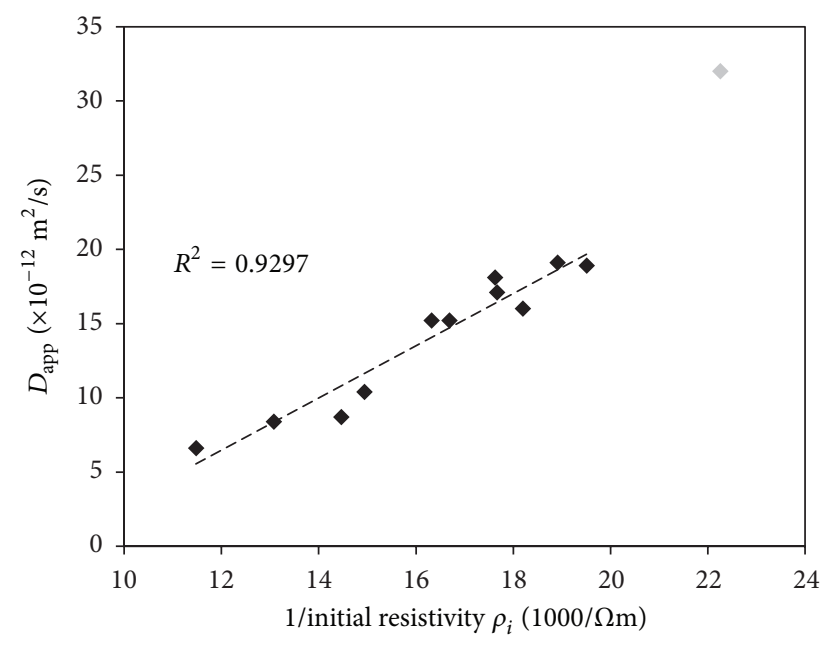

FIGURE 15: Correlation between inverse of average initial electrical resistivity and apparent chloride diffusion coefficient for all concrete types. The grey data point was not taken into account for linear regression.

NS addition, the reduction of median pore diameter was probably enough to slightly reduce the diffusion coefficient (see Table 4) [13].

Comparing the electrical resistivity in Figure 14(a) with that in Figure 14(c), an addition of $0.5 \%$ NS increased the resistivity of concrete with all $\mathrm{w} / \mathrm{b}$ ratios, while the addition of $1.5 \%$ NS only elevated that of concrete with $\mathrm{w} / \mathrm{b}=0.5$. The chloride diffusivity and the electrical resistivity are both dependent on permeability of ions inside pore solution. As a consequence, the apparent chloride diffusion coefficient has linear correlation with inverse of the resistivity [33] and this correlation was obtained and shown in Figure 15 with a linear regression as specified in the figure. According to Figure 15, a decrease in the diffusion coefficient corresponds to an increase in electrical resistivity with a good linear proportionality. The grey data point is not included in the linear regression and this deviation from the linearity represents clearly the unexpected variation of the chloride diffusion coefficient of this data point as compared to other data; see Section 3.3. The $R$-squared of linear regression is approximately $93 \%$ and it means that linear model could explain appropriately the variability of the data around the model.

According to Figures 14(a) and 14(b), NS was not effective to increase carbonation resistance of concrete with $\mathrm{w} / \mathrm{b}=$ 0.65 and $0.5(0.5 \%$ and $1 \% \mathrm{NS})$, while incorporation of the similar dosages in concrete with $\mathrm{w} / \mathrm{b}=0.55$ caused relative reduction in carbonation coefficient. NS addition had negative effect on resistance to carbonation of concrete with $\mathrm{w} / \mathrm{b}=0.65$. Regarding the fact of no variation in porosity and $\mathrm{CH}$ content of $\mathrm{w} / \mathrm{b}=0.65$ with $1.5 \% \mathrm{NS}$ with respect to control, probably the reason could be that $\mathrm{C}-\mathrm{S}-\mathrm{H}$ became more impervious to neutralization and the carbonation front went faster than reference. Not only $\mathrm{CH}$ can be neutralized in carbonation reaction, but also carbonation of C-S-H is possible when $\mathrm{CH}$ is depleted. NS modifies the internal structure of the C-S-H gel stabilizing calcium ions [34].

According to the discussion above, possible beneficial effects of NS addition on the durability properties of concrete should not be inferred from beneficial effects on compressive strength. An equivalent NS addition into concrete with various $\mathrm{w} / \mathrm{b}$ ratios did not produce similar effect on durability properties. No consistent trend as a function of $\mathrm{w} / \mathrm{b}$ ratio was detected for the effectiveness of NS on durability properties of concrete, whilst effectiveness of NS addition on compressive strength decreased with decreasing $\mathrm{w} / \mathrm{b}$ ratio.

\section{Conclusions}

This paper investigated the effects of NS on compressive strength and durability properties of concrete with various $\mathrm{w} / \mathrm{b}$ ratios. From the results, the following conclusions can be drawn.

(i) Beneficial effects of NS addition on compressive strength should not be taken as proof of similarly beneficial effects on durability properties.

(ii) Effectiveness of a certain NS dosage on compressive strength and durability properties for high strength concrete mixes was different than low strength mixes. By the incorporation of $1.5 \%$ NS into concrete with $\mathrm{w} / \mathrm{b}=0.65,0.55$, and 0.5 , strength gains of $41 \%, 6.5 \%$, and nil, respectively, were obtained.

(iii) Durability properties of concrete with different $w / b$ ratios showed highly varying tendency by increasing NS dosage. For a certain NS dosage, analogous effect on concrete with different $w / b$ ratios was not detected. Furthermore, the tendency of the variations as a function of $w / b$ ratio was not preserved by increasing NS content.

(iv) Sorptivity and water absorption exhibited negligible change after NS addition for $\mathrm{w} / \mathrm{b}=0.65$ and 0.5 ; only for $\mathrm{w} / \mathrm{b}=0.55$ they were clearly reduced by NS addition, having an optimum on $1 \%$.

(v) Apparent chloride diffusion coefficient of concrete decreased with $0.5 \%$ NS addition for $\mathrm{w} / \mathrm{b}=0.65$ and 0.55 . However, it did not decrease with the addition of higher NS contents as effective as $0.5 \%$ NS. For $\mathrm{w} / \mathrm{b}=0.5$, slight reduction was found only after $1.5 \%$ NS addition.

(vi) The electrical resistivity of saturated specimen moderately increased after the addition of $0.5 \%$ NS for all $\mathrm{w} / \mathrm{b}$ ratios. For $\mathrm{w} / \mathrm{b}=0.5$, it also increased for $1.5 \%$ NS addition.

(vii) NS addition resulted in detrimental effect on carbonation coefficient for $\mathrm{w} / \mathrm{b}=0.65$ and the carbonation coefficient was elevated from the reference of 24 to $29.3 \mathrm{~mm} / \sqrt{ }$ year by $1 \% \mathrm{NS}$, in contrast to that of $\mathrm{w} / \mathrm{b}=0.55$ which was reduced from the reference of 20.4 to $16 \mathrm{~mm} / \sqrt{ }$ year by the same NS content. Calcium hydroxide content of concrete was found to be reduced only in case of $\mathrm{w} / \mathrm{b}=0.5$. 
(viii) NS clearly refined porosity microstructure of $\mathrm{w} / \mathrm{b}=$ 0.55 and $1 \%$ NS addition compared to reference. Limited refinement of macroporosity was observed by $1.5 \% \mathrm{NS}$ addition to $\mathrm{w} / \mathrm{b}=0.5$. Gel porosity of $\mathrm{w} / \mathrm{b}=$ 0.65 increased considerably with $1.5 \%$ NS addition.

\section{Competing Interests}

The authors declare that they have no competing interests.

\section{Acknowledgments}

The work received partial funding by the European IRSES project "Development of Sustainable Electrochemical Corrosion Protection Systems for Reinforced Concrete Structures" (DOSECOPS project) and the Shenzhen Strategic Emerging Industry Development Special Fund (no. JCYJ20150625102603853).

\section{References}

[1] M. V. Diamanti, F. Lollini, M. P. Pedeferri, and L. Bertolini, "Mutual interactions between carbonation and titanium dioxide photoactivity in concrete," Building and Environment, vol. 62, pp. 174-181, 2013.

[2] H. Li, H.-G. Xiao, J. Yuan, and J. Ou, "Microstructure of cement mortar with nano-particles," Composites Part B: Engineering, vol. 35, no. 2, pp. 185-189, 2004.

[3] A. Nazari and S. Riahi, "Abrasion resistance of concrete containing $\mathrm{SiO}_{2}$ and $\mathrm{Al}_{2} \mathrm{O}_{3}$ nanoparticles in different curing media," Energy and Buildings, vol. 43, no. 10, pp. 2939-2946, 2011.

[4] J. Song and S. Liu, "Properties of reactive powder concrete and its application in highway bridge," Advances in Materials Science and Engineering, vol. 2016, Article ID 5460241, 7 pages, 2016.

[5] P. Hou, S. Kawashima, D. Kong, D. J. Corr, J. Qian, and S. P. Shah, "Modification effects of colloidal nanoSiO 2 on cement hydration and its gel property," Composites Part B: Engineering, vol. 45, no. 1, pp. 440-448, 2013.

[6] S. Haruehansapong, T. Pulngern, and S. Chucheepsakul, "Effect of the particle size of nanosilica on the compressive strength and the optimum replacement content of cement mortar containing nano- $\mathrm{SiO}_{2}$," Construction and Building Materials, vol. 50, pp. 471-477, 2014.

[7] J. Björnström, A. Martinelli, A. Matic, L. Börjesson, and I. Panas, "Accelerating effects of colloidal nano-silica for beneficial calcium-silicate-hydrate formation in cement," Chemical Physics Letters, vol. 392, no. 1-3, pp. 242-248, 2004.

[8] F. U. A. Shaikh and S. W. M. Supit, "Chloride induced corrosion durability of high volume fly ash concretes containing nano particles," Construction and Building Materials, vol. 99, pp. 208225, 2015.

[9] M. Jalal, E. Mansouri, M. Sharifipour, and A. R. Pouladkhan, "Mechanical, rheological, durability and microstructural properties of high performance self-compacting concrete containing $\mathrm{SiO} 2$ micro and nanoparticles," Materials and Design, vol. 34, pp. 389-400, 2012.

[10] A. M. Said, M. S. Zeidan, M. T. Bassuoni, and Y. Tian, "Properties of concrete incorporating nano-silica," Construction and Building Materials, vol. 36, pp. 838-844, 2012.
[11] R. Yu, P. Spiesz, and H. J. H. Brouwers, "Effect of nano-silica on the hydration and microstructure development of Ultra-High Performance Concrete (UHPC) with a low binder amount," Construction and Building Materials, vol. 65, pp. 140-150, 2014.

[12] H. Du, S. Du, and X. Liu, "Durability performances of concrete with nano-silica," Construction and Building Materials, vol. 73, pp. 705-712, 2014.

[13] G. Quercia, P. Spiesz, G. Hüsken, and H. J. H. Brouwers, "SCC modification by use of amorphous nano-silica," Cement and Concrete Composites, vol. 45, pp. 69-81, 2014.

[14] M.-H. Zhang, J. Islam, and S. Peethamparan, "Use of nano-silica to increase early strength and reduce setting time of concretes with high volumes of slag," Cement and Concrete Composites, vol. 34, no. 5, pp. 650-662, 2012.

[15] T. Ji, "Preliminary study on the water permeability and microstructure of concrete incorporating nano- $\mathrm{SiO}_{2}$," Cement and Concrete Research, vol. 35, no. 10, pp. 1943-1947, 2005.

[16] A. Leemann and F. Winnefeld, "The effect of viscosity modifying agents on mortar and concrete," Cement and Concrete Composites, vol. 29, no. 5, pp. 341-349, 2007.

[17] F. U. A. Shaikh, S. W. M. Supit, and P. K. Sarker, "A study on the effect of nano silica on compressive strength of high volume fly ash mortars and concretes," Materials and Design, vol. 60, pp. 433-442, 2014.

[18] E. Hala, I. S. Mohamed, and S. E. Muhammad, "Effect of nano silica de-agglomeration, and methods of adding superplasticizer on the compressive strength, and workability of nano silica concrete," Civil and Environmental Research, vol. 3, no. 2, pp. 21-34, 2013.

[19] S. W. M. Supit and F. U. A. Shaikh, "Durability properties of high volume fly ash concrete containing nano-silica," Materials and Structures, vol. 48, pp. 2431-2445, 2015.

[20] J. I. Tobón, J. Payá, and O. J. Restrepo, "Study of durability of Portland cement mortars blended with silica nanoparticles," Construction and Building Materials, vol. 80, pp. 92-97, 2015.

[21] M. Zahedi, A. A. Ramezanianpour, and A. M. Ramezanianpour, "Evaluation of the mechanical properties and durability of cement mortars containing nanosilica and rice husk ash under chloride ion penetration," Construction and Building Materials, vol. 78, pp. 354-361, 2015.

[22] R. Madandoust, E. Mohseni, S. Y. Mousavi, and M. Namnevis, "An experimental investigation on the durability of selfcompacting mortar containing nano- $\mathrm{SiO}_{2}$, nano- $\mathrm{Fe}_{2} \mathrm{O}_{3}$ and nano-CuO," Construction and Building Materials, vol. 86, pp. 44-50, 2015.

[23] E. Mohseni, B. M. Miyandehi, J. Yang, and M. A. Yazdi, "Single and combined effects of nano- $\mathrm{SiO}_{2}$, nano- $\mathrm{Al}_{2} \mathrm{O}_{3}$ and nano$\mathrm{TiO}_{2}$ on the mechanical, rheological and durability properties of self-compacting mortar containing fly ash," Construction and Building Materials, vol. 84, pp. 331-340, 2015.

[24] H. Madani, A. Bagheri, T. Parhizkar, and A. Raisghasemi, "Chloride penetration and electrical resistivity of concretes containing nanosilica hydrosols with different specific surface areas," Cement and Concrete Composites, vol. 53, pp. 18-24, 2014.

[25] J. S. Belkowitz, W. L. B. Belkowitz, K. Nawrocki, and F. T. Fisher, "Impact of nanosilica size and surface area on concrete properties," ACI Materials Journal, vol. 112, no. 3, pp. 419-427, 2015.

[26] S. Rao, P. Silva, and J. De Brito, "Experimental study of the mechanical properties and durability of self-compacting mortars with nano materials $\left(\mathrm{SiO}_{2}\right.$ and $\left.\mathrm{TiO}_{2}\right)$," Construction and Building Materials, vol. 96, pp. 508-517, 2015. 
[27] S. Lim and P. Mondal, "Effects of nanosilica addition on increased thermal stability of cement-based composite," ACI Materials Journal, vol. 112, no. 2, pp. 305-316, 2015.

[28] "UNI CEN/TS 12390-11, determination of chloride resistance of concrete unidirectional diffusion," Tech. Rep. CEN/TS 104, Concrete and Related Products, 2010.

[29] UNI, "Products and systems for the protection and repair of concrete structures-test methods-determination of chloride content in hardened concrete," UNI EN 14629, Ente Nazionale Italiano di Unificazione, 2007.

[30] R. Polder, C. Andrade, B. Elsener et al., "Test methods for on site measurement of resistivity of concrete," Materials and Structures, vol. 33, no. 10, pp. 603-611, 2000.

[31] S. Mindess, J. F. Young, and D. Darwin, Concrete, Prentice Hall, Upper Saddle River, NJ, USA, 2nd edition, 2003.

[32] A. M. Neville, Properties of Concrete, John Wiley \& Sons, New York, NY, USA, 1973.

[33] R. B. Polder and W. H. A. Peelen, "Characterisation of chloride transport and reinforcement corrosion in concrete under cyclic wetting and drying by electrical resistivity," Cement and Concrete Composites, vol. 24, no. 5, pp. 427-435, 2002.

[34] J. J. Gaitero, I. Campillo, and A. Guerrero, "Reduction of the calcium leaching rate of cement paste by addition of silica nanoparticles," Cement and Concrete Research, vol. 38, no. 8-9, pp. 1112-1118, 2008. 

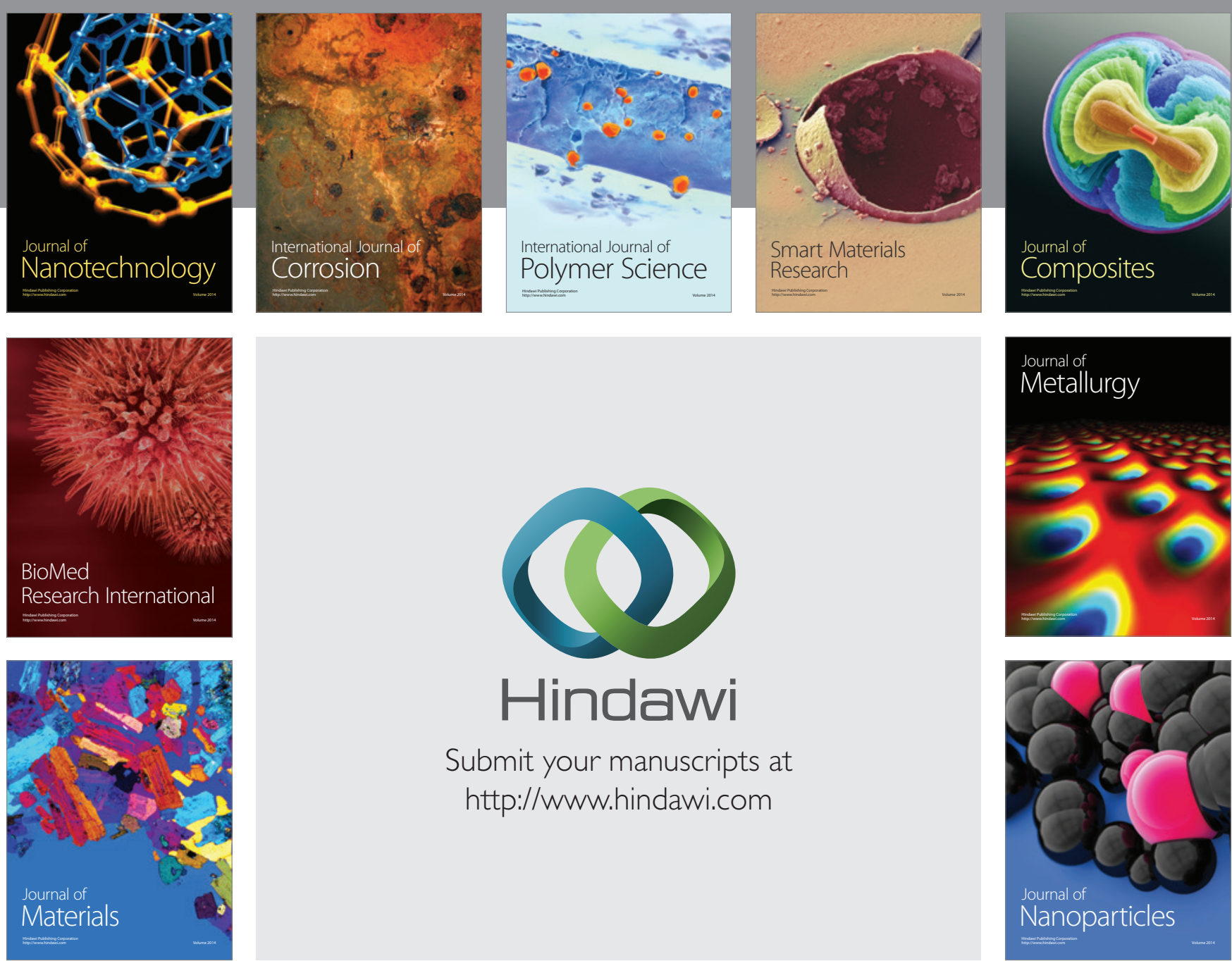

\section{Hindawi}

Submit your manuscripts at

http://www.hindawi.com

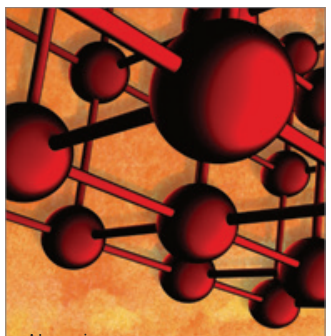

Materials Science and Engineering
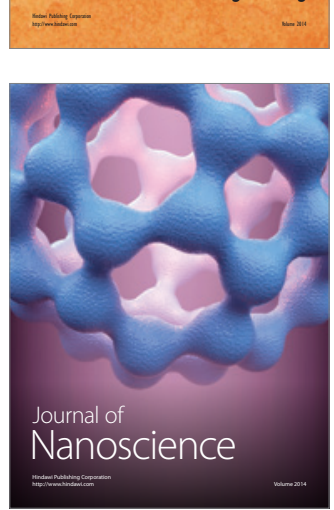
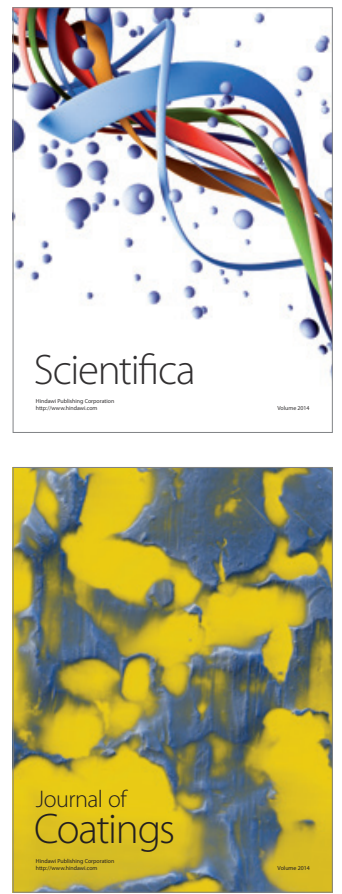
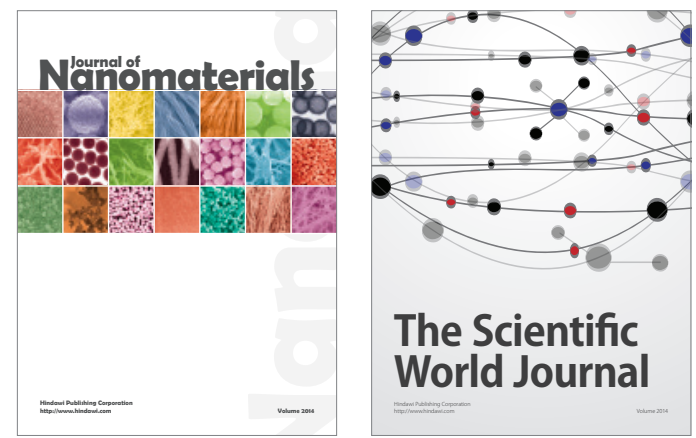

The Scientific World Journal
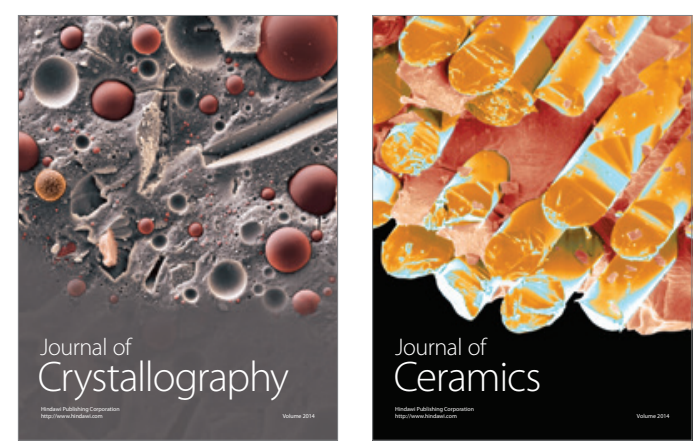
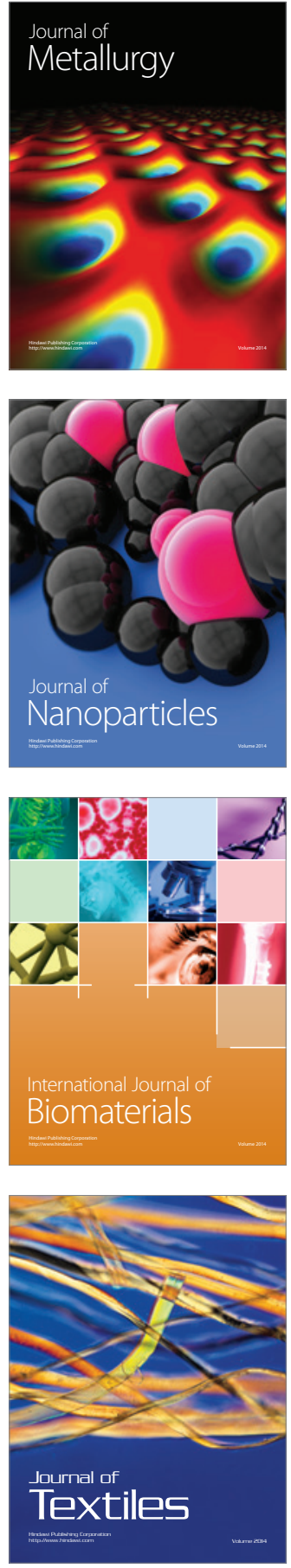